\title{
Stochastic-dynamic modelling of farm-level investments under uncertainty
}

\section{Journal Article}

\section{Author(s):}

Spiegel, Alisa; Britz, Wolfgang; Djanibekov, Utkur; Finger, Robert (D)

\section{Publication date:}

2020-05

\section{Permanent link:}

https://doi.org/10.3929/ethz-b-000405669

\section{Rights / license:}

Creative Commons Attribution-NonCommercial-NoDerivatives 4.0 International

Originally published in:

Environmental Modelling \& Software 127, https://doi.org/10.1016/j.envsoft.2020.104656 


\section{Postprint}

This is the accepted version of a paper published in Environmental Modeling \& Software This paper has been peer-reviewed but does not include the final publisher proof-corrections or journal pagination.

\section{Citation for the original published paper:}

Spiegel, A., Britz, W., Djanibekov, U. Finger, R. (2020). Stochastic-dynamic modelling of farm-level investments under uncertainty. Environmental Modelling and Software 127, 104656

https://doi.org/10.1016/j.envsoft.2020.104656

Access to the published version may require subscription.

N.B. When citing this work, cite the original published paper. 


\title{
STOCHASTIC-DYNAMIC MODELLING OF FARM-LEVEL INVESTMENTS UNDER UNCERTAINTY
}

\begin{abstract}
In the light of uncertainties, high initial costs, and temporal managerial flexibility, the real options approach has gained interest as a valuation tool for different types of natural resources management problems. Yet, neither real options valuation method excels under consideration of variability of resource endowments, returns-to-scale and predefined sizes of options. We fill the methodological gap by developing a method based on Monte Carlo simulation, scenario tree reduction, and stochastic programming that is advantageous for valuing real options where timing, scale and interactions among constraints and alternatives matter. The method advances in straightforward conversion of deterministic programming applications based on the classical net present value approach into a real options framework, and in introducing complexity into existing real options models. We illustrate the method with a case study featuring investment options regarding the adoption, coppicing, and conversion of perennial biomass energy production systems.
\end{abstract}

\section{Highlights}

- We offer a new method of spatial and temporal optimization of natural resource use

- We use Monte Carlo simulation, scenario tree reduction and stochastic programming

- The method allows for multiple uncertainties, non-linearity, various restrictions

- The method ensures computational efficiency while being tractable and intuitive

- The method produces comprehensive results and allows risk analyses

\section{Keywords}

Investment decision; real options; Monte Carlo simulation; stochastic programming; perennial crop.

\section{Software availability}

The open source model, including a Graphical User Interface that allows straightforward changes to the initial parameters, and all related documentation are available in Spiegel et al. (2017). 


\section{Introduction}

Land use changes and the resulting environmental impacts are to a large extent driven by economic decision making and management. Because economic consequences of these decisions span into future periods, many land use decisions have an investment character. This also implies that multiple uncertainties about future environmental, economics and institutional developments matter for such decision making (Uusitalo et al., 2015; Douglas-Smith et al., 2020). ${ }^{1}$ Besides facing uncertainties, investments related to land and more general natural resource management are often subject to high initial sunk costs and temporal flexibility. For instance, in tree plantation management, decision makers are often interested to identify when to set-up a plantation and to cut trees. The three components - uncertainty, temporal flexibility, and sunk costs - can constitute a positive value of waiting, i.e., postponing the investment decision can be beneficial. That leads to the problem to find the value of an asset, which allows to invest at any time point in the future until this possibility expires - the domain of the real options approach (Dixit and Pindyck, 1994). An example is the current value of a piece of land, which one might at some future time point convert into a plantation, under uncertain future prices and yields. Finding that value provides the information how likely the set-up at certain time points can be. These viewpoints motivate the application of the real options approach to different types of land and natural resources management problems (Alonso-Ayuso et al., 2014; Djanibekov and Villamor, 2017; Feng and Ryan, 2013; Sagastizábal, 2012; Simoglou et al., 2014; Tee et al., 2014; van Ackooij and Sagastizábal, 2014).

Furthermore, large management projects are usually characterized with (1) competition among multiple activities for (quasi-)fixed resources ${ }^{2}$, e.g., limited labor and machinery capacity; (2) returns-to-scale as, e.g., technology adoption requiring acquisition of a license or new skills; (3) investment goods of predefined sizes, e.g., an indivisible land plot; (4) investment scale; (5) multi-stage decisions, e.g., finding an optimal distribution of extraction over time. These aspects are relevant in assessments of, for instance, agricultural infrastructure projects, setting

\footnotetext{
${ }^{1}$ Hereinafter we refer by "uncertainty" to both positive and negative deviations, e.g. from price and yield expectations, to underline potential benefits of variability and avoid the negative connotation linked to the term "risk" and downside risk aversion (see, e.g., Finger et al., 2018).

${ }^{2}$ We explicitly refer to quasi-fixed resources, in order to highlight that resources could be expanded in the longrun, e.g., by hiring extra labor or renting or buying more land. Yet, we do not consider this possibility in our model.
} 
up plantations, climate change mitigation and adaptation measures, or resource extraction (e.g., Marinoni et al., 2009; O’Regan and Moles, 2001; Viaggi et al., 2013). Due to explicitly or implicitly inherent restrictions, existing models fail to (jointly) capture the aspects (1)-(5), while also considering temporal flexibility of a project (Bouchard and Warin, 2012; Bartolini and Viaggi, 2012; Feng and Ryan, 2013; Regan et al., 2015).

In most cases, real options are valued using numerical methods as closed-form solutions do not exist (Black and Scholes, 1973; Geske and Johnson, 1984). There are two prominent approaches when multiple potential time points for the investment are considered: firstly, stochastic simulation based on a binomial (or trinomial) scenario tree (Cox et al., 1979; Trigeorgis, 1991) and, secondly, Monte Carlo simulation (Boyle, 1977), including the computationally more efficient Least Squares Monte Carlo simulation method (Longstaff and Schwartz, 2001). A binomial (or trinomial) scenario tree is an intuitive and generic approach, however, it suffers from the curse of dimensionality and leads to branches with exploding values or values close to zero already under rather conservative assumptions about variance at the nodes (Lander and Pinches, 1998, pp. 545-546), limiting its applicability to multi-stage investment options and longtime horizons. To give an example of a multi-stage option: the possibility to cut trees after a flexibly determined growth period is clearly conditioned on an initial set-up of the planation. Least Squares Monte Carlo simulation deals with multi-stage options efficiently, yet it is often criticized for sensitivity to the choice of functional form in the regression step (Stentoft, 2004, p. 136), especially if the dimension increases (Bouchard and Warin, 2012, p. 216).

Our paper proposes a valuation method for problems with multiple potential investment points and related subsequent temporal flexible decisions that can cover simultaneously characteristics such as returns-to-scale, indivisibilities, quasi-fixed resources or multiple competing uses of assets. Addressing the advantages and shortcoming of existing approaches, we propose a valuation method that combines and benefits of scenario tree and simulation methods by applying a scenario tree reduction technique to the outcome of a Monte Carlo simulation. This controls for dimensionality and obtains an advanced scenario tree that enters stochastic programming, which then values real options. In contrast to Least Squares Monte Carlo simulation, this method does not approximate fitted payoffs and hence the optimal investment decisions with one function, but rather considers the fragmented distribution of self-contained expected payoffs. Each node of the constructed scenario tree summarizes draws of the stochastic variables and their respective added-up probabilities. Using stochastic programming, 
we obtain an optimal strategy comprised of the distribution of (quasi-)fixed resources between competing investment options for each of these nodes under consideration of all possible developments of the stochastic variable. The results are hence intuitive and straightforward to communicate. Furthermore, sensitivity and other types of analysis can be easily exercised using our method. Finally, it advances in straightforward conversion of deterministic programming applications based on the net present value approach into a real options framework, as well as in introducing complexity into existing real options models.

In order to illustrate the method and demonstrate its applicability to complex real-world examples, we choose an example related to perennial energy crop cultivation in Germany, i.e., dynamic land use decision. Specifically, a farmer considers redistributing land from annual crops to a perennial energy crop, which binds the land for a longer time period while the farmer faces uncertainty (at least) related to biomass output prices. That case study depicts an investment project, where not only timing, but also investment scale and interactions among alternatives are relevant due to competition for resources. Introducing perennial energy crops, and in particular sustainable biomass energy production systems such as short-rotation coppice (SRC), also in agricultural landscape can have manifold environmental advantages, including greenhouse gas (GHG) emission reduction (Lewandowski 2015), biodiversity protection, soil erosion reduction (Rokwood 2014; Adams and Lindegaard 2016), and increasing soil fertility (Tolbert et al. 2002). Furthermore, SRC is characterized with higher net energy ratio (i.e., the ratio between energy output and fossil energy input), compared with annual energy crops (Heller et al. 2003; Keoleian and Volk 2005; Eder et al. 2009). Nevertheless, farmers in the EU are often reluctant to adopt SRC (Dimitriou et al. 2011; von Wühlisch 2016; Warren et al. 2016; Parra-López et al. 2017), despite farm-level policy support introduced in many European countries in order to promote perennial energy crops (Hart 2015; Lindegaard et al. 2016). Existing studies that analyze profitability of adopting SRC provide ambiguous conclusions. According to the review of 37 relevant studies made by Hauk et al. (2014), 43\% report economic viability of SRC; 19\% report economic disadvantages; and 38\% mixed results that depend on particular assumptions. Based upon existing models, our method allows relaxing restrictive assumptions and hence revealing additional economic incentives and disincentives of SRC adoption.

The remainder of this paper is organized as follows. Section 2 provides a methodological background of option valuation and identifies the gaps addressed by the proposed method. 
Section 3 provides a general description of the method. Section 4 illustrates the method applied to the case study. Section 5 presents the main empirical findings from the case study. Section 6 discusses further application potential for the proposed method. Section 7 concludes our study.

\section{State of the art}

Analytical solutions for real options valuation (e.g., Black and Scholes, 1973; Geske and Johnson, 1984) are elegant from a scholarly perspective, but are often deemed inappropriate for practical application due to restrictive assumptions required (e.g., regarding stochastic processes). If such is the case, a numerical method must be employed instead (Trigeorgis, 1996; Regan et al., 2015). Cetinkaya and Thiele (2014, p. 12) distinguish between methods that approximate the underlying stochastic process and methods that approximate partial differential equations (see, overview of latter in Trigeorgis, 1996). The most well-known method that approximates partial differential equations - the Black-Scholes-Merton model (Merton, 1973) — was initially designed and is well suited for the valuation of simple European options (Regan et al., 2015, p. 146), i.e., options that can be exercised at some pre-defined point of time in the future or never - a rather restrictive assumption for management of natural resources. More sophisticated American options - the ones that can be exercised at any time within a certain time period - and multi-stage options are typically valued by approximating stochastic process methods. These methods can further be divided between Monte Carlo simulation (Boyle, 1977), including the computationally more efficient LSMC method (Longstaff and Schwartz, 2001), and scenario tree approximation.

Scenario tree approximation usually implies either a binomial lattice or a binomial scenario tree (Brandão and Dyer, 2005; Smith, 2005). The core characteristic of a lattice model is that in a stochastic process a movement up, followed by a movement down of an uncertain parameter, provides the same outcome, as a movement down, followed by a movement up (Smith, 2005, p. 92). An (approximate) optimal value of investment options depicted by the constructed scenario tree or lattice is then found by dynamic programming (Dixit and Pindyck, 1994, pp. 140-147; Guthrie, 2009, pp. 88-92) that are widely used to analyze investment decisions in a quantitative and relatively transparent way, including stochastic programming applications (Brandes et al., 1980; Haigh and Holt, 2002). Examples of real options valuation with stochastic programming include, energy economics (Feng and Ryan, 2013; Sagastizábal, 2012; Simoglou et al., 2014; van Ackooij and Sagastizábal, 2014), managing project portfolios (Beraldi et al., 2013), and natural resource extraction (Alonso-Ayuso et al., 2014). One of the main 
disadvantages of scenario tree approximation over a binomial lattice is that it can quickly threaten computational capacity as the number of time periods increases (Lander and Pinches, 1998, pp. 545-546), since a binomial lattice requires $[n(n+1) / 2]$, and a binomial tree requires $2^{n}$ final leaves for $n$ time periods. Furthermore, development of stochastic parameters in a binomial tree or lattice with chained relative ups and downs in each node can lead to unrealistic values after a few points in time, since the already rather conservative assumptions about variance at any node can imply exploding branches. In this case, the standard approach is to aggregate the time periods down to the desired number, lumping them together (Bartolini and Viaggi, 2012; Feng and Ryan, 2013). Such aggregation, however, loses information relevant for real-world applications, when, e.g., yearly decisions are depicted by multi-year steps.

The alternative Least Squares Monte Carlo simulation method evolves from the core finding that optimal strategy is determined by the conditional expectations of the value of postponing investment; and that these conditional expectations can be estimated using simulation results (Longstaff and Schwartz, 2001, p. 114). Thus, the method consists of the following three steps: (i) simulation of the payoffs of investing in every time period and keeping it in previous periods; (ii) regression of those payoffs using least squares; and (iii) specification of the optimal strategy based on estimated regression and fitted payoffs. Least Squares Monte Carlo simulation is considered a powerful method for the valuation of real options and is widely used (Abadie and Chamorro, 2009; Sabour and Poulin, 2006; Zhu and Fan, 2011). One disadvantage of the Least Squares Monte Carlo simulation method is that a functional form must be assumed for estimation of the Lagrangian, which can be crucial for determining optimal strategy (Stentoft, 2004, p. 136). Although several papers addressed this issue (Haugh and Kogan, 2004; Létourneau and Stentoft, 2014; Rogers, 2002), to date there is no general payoff independent choice algorithm that works for higher dimensional problems (Bouchard and Warin, 2012, p. 216).

Due to computational and methodological challenges of introducing organizational realities and constraints into a theoretical model, empirical implementation of real options analysis is rather limited (Lander and Pinches, 1998; Regan et al., 2015; Trigeorgis and Reuer, 2017; Trigeorgis and Tsekrekos, 2018). Although the limitations listed above can be legitimate for short-term standing-alone investment options, they threaten valuation of large management projects that not only involve multi-stage investment, but also compete for (quasi-) scarce resources. This implies that (changes in) returns to inputs and possible management adjustments resulting from 
resource reallocation also need to be considered. These interactions among endowment constraints and alternative activities are especially crucial in the context of returns-to-scale and/or a set of investment options of predefined sizes (i.e., binary decision variables): such as investments in indivisible assets, investments characterized by a high share of transaction or other (quasi-) fixed costs, and investments that affect the availability of resources over time for alternative uses. In such cases, both the timing and scale of investment option are at issue. Yet, none of the methods discussed above are suited for these problem conditions. Due to the curse of dimensionality, a binomial scenario tree hampers valuation of multi-stage investment options, particularly over a longtime horizon. Least Squares Monte Carlo simulation impedes the choice of Lagrangian function under high dimensionality, and requires solving with a programming model for each single fitted payoff if interactions among constraints and alternative activities are considered, which threatens its computational efficiency. Trigeorgis and Tsekrekos (2018) conducted an extensive literature review on real options analyses and concluded that there is a room for alternative numerical methods, especially methods that are able to relax necessarily restrictive assumptions and thus facilitate more realistic applications, which is the motivation for our research. The method we propose inherits the transparency of a scenario tree and programming approaches and outperforms Least Squares Monte Carlo simulation in terms of computational capacity and required assumptions. The method is particularly relevant if alternative activities, returns-to-scale, indivisible assets, and resource endowments and other constraints are jointly considered.

\section{General methodology}

The section provides a description of the proposed method. Major equations and assumptions used for our illustrative example can be found in the next section. The method we propose includes four main steps (Fig. 1). First, we define the (state contingent) decision variables of the problem and the related real options, i.e., (multi-stage) investment with a potential positive value of waiting before exercising it. Integers, including binaries, enable differentiation among investment options with predefined sizes and reflect returns-to-scale. Second, the relationships (i.e., equations and constraints) among these decision variables are specified, including lagged relationships between time points, and then combined into a programming model. In this step, we add the payoff function (e.g., net present value) subject to constraints, including resource endowments. Hence, the first two steps design a deterministic mixed-integer linear programming model. Many operations research problems involving the timing of production 
processes and related investment decisions are solved in that format, and thus employ already these two steps (Flisberg et al., 2014; Venter et al., 2018; Yan and Ji, 2017). This problem can be extended to a real option problem as discussed next. Third, we identify exogenous stochastic variables within the model, introduce different future outcomes (states), and the related state contingent decision variables. In order to convert the deterministic version into its stochastic programming equivalent, four additional elements are added: (i) the decision variables carry an additional index for the decision node (i.e., state); (ii) an ancestor matrix is introduced that reflects the dynamic order of the nodes in the decision tree; (iii) outcomes for the stochastic parameters for each state are defined; and (iv) probabilities are assigned to each node. In particular, we choose a distribution to account for uncertainty with respect to parameter(s) applying one of the existing forecasting techniques ${ }^{3}$. Based on the chosen distribution, we create Monte Carlo scenarios, and let a scenario tree reduction technique construct a reduced scenario tree of a desired size with (aggregated) probabilities for selected nodes approximating the Monte Carlo scenarios. Finally, we employ the stochastic programming for the valuation of investment options.

${ }^{3}$ Forecasting has developed as a separate research discipline and includes a number of available methods. Fildes et al. (2017) distinguish between (i) extrapolative methods; (ii) causal and multivariate econometric methods; and (iii) computer-intensive data-mining methods of forecasting. We leave the choice of a forecasting method for a particular exogenous stochastic variable out of scope of the paper, as our method implies no restriction in terms of selected forecasting technique and the resulting distribution, as long as Monte Carlo scenarios can be generated. 


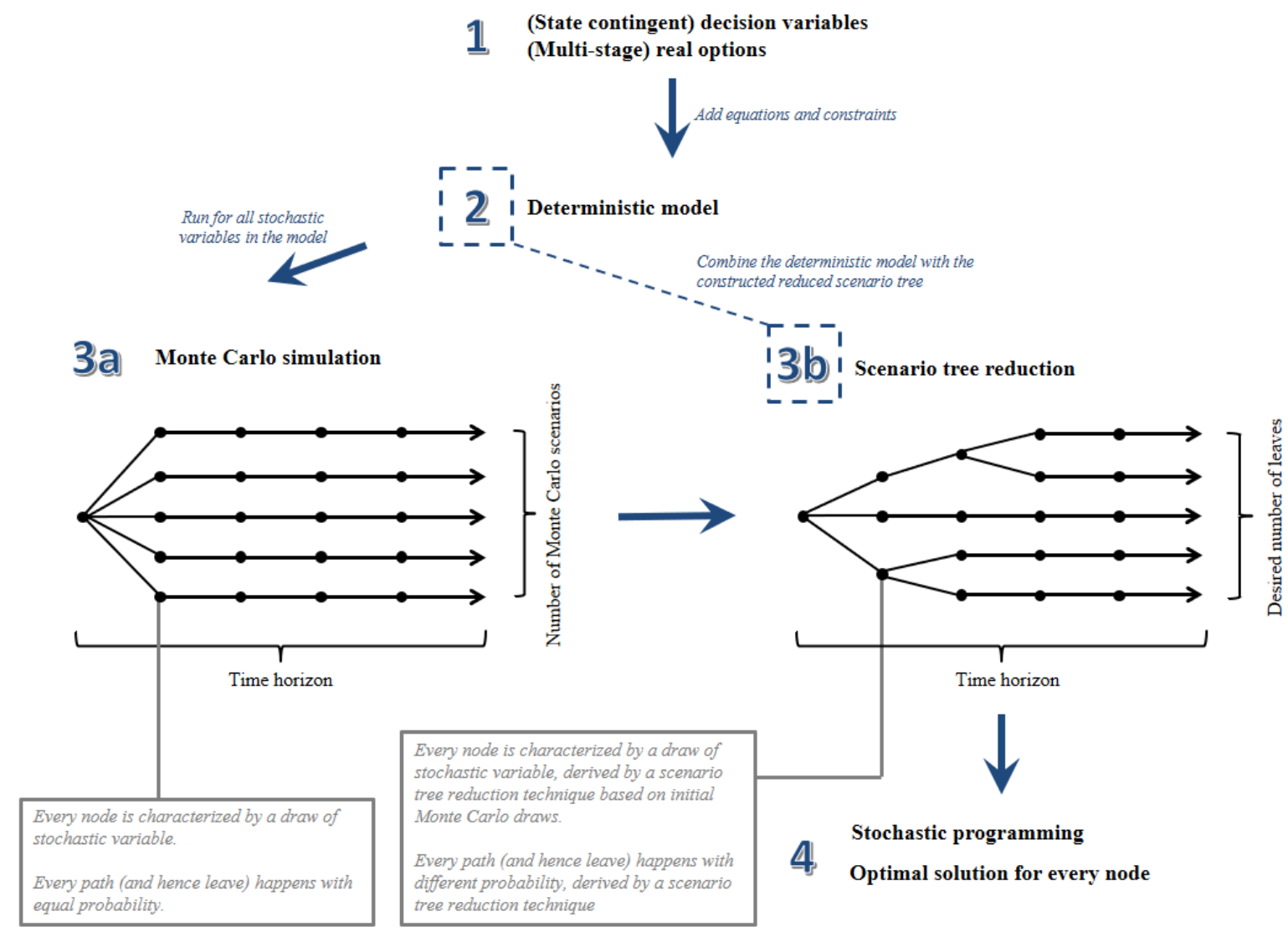

Fig. 1 The main four steps of the proposed method. Note: Steps 1, 2, 3b, and 4 are exercised in GAMS; step 3a, although being able to be exercised in GAMS as well, is exercised using JAVA libraries, in order to advance in computational speed. For steps $3 b$ and 4 we used a scenario tree reduction technique SCENRED2 and a solver CPLEX.

There are several important details in the third step concerning how the outcomes and related probabilities are constructed. We assume stochastic processes for the stochastic components and run Monte Carlo simulations that result in a large scenario tree that is not solvable numerically due to the curse of dimensionality. We reduce the size of the tree without losing too much information about the underlying distributions by employing the tree reduction and construction algorithm of Heitsch and Römisch, (2008). Similar to a Gaussian quadrature, which describes a probability density function with few characteristic values and their probability mass, this algorithm picks representative nodes and assigns probabilities to capture the approximate distribution in original trees (Fig. 2). Methods generating a scenario tree can be summarized as aggregating nodes and stages, and trimming or refining trees (Consigli and Dempster, 1998; Dempster, 2006; Dempster and Thompson, 1999; Frauendorfer and Marohn, 1998; Klaassen, 1998) differing only in the algorithm of selecting nodes and paths to aggregate. A practical advantage of the tree reduction and construction algorithm developed by Heitsch and Römisch, (2008) is a GAMS tool, SCENRED2. 

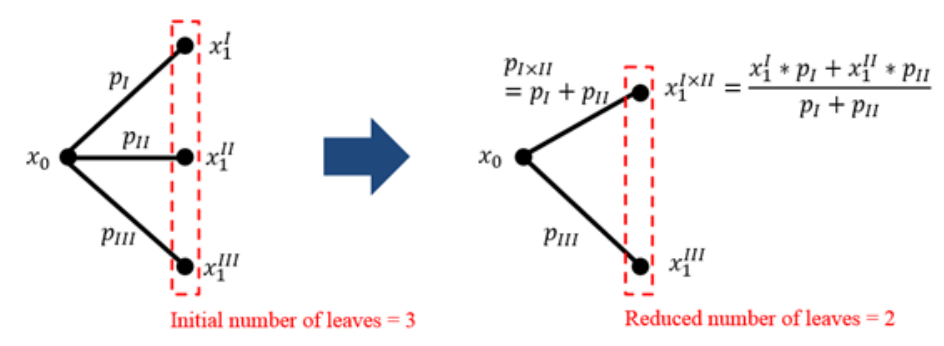

Fig. 2 The basic principle of scenario tree reduction. Note: $x_{\mathbf{0}}$ stays for the currently observed value; $\boldsymbol{x}_{1}^{I}, \boldsymbol{x}_{\mathbf{1}}^{\boldsymbol{I I}}, \boldsymbol{x}_{\mathbf{1}}^{\boldsymbol{I I I}}$, and $\boldsymbol{x}_{\mathbf{1}}^{\boldsymbol{I} \times \boldsymbol{I I}}$ stay for the possible realizations in the next time period; $\boldsymbol{p}_{\boldsymbol{I}}, \boldsymbol{p}_{I I}, \boldsymbol{p}_{I I I}$, and $\boldsymbol{p}_{I \times I I}$ stay for the respective probabilities.

The algorithm can also be depicted graphically as lumping together neighboring nodes and branches in the tree into bigger ones, where the thickness represents probability mass. The algorithm directly provides the ancestor matrix; SCENRED2 implies a single parent for each node in the reduced scenario tree. In particular, we opt to use a pre-defined number of final leaves and hence pre-determine the number of equations and variables in the model, letting the algorithm decide which nodes to maintain. There is no well-established approach to determine the optimal number of leaves in a reduced scenario tree. The choice, however, should be case study specific and reflect a tradeoff between accuracy and solution time: more leaves lead to higher precision in outcomes while increasing the solution time (Dupačová et al., 2000, p. 30). The extreme case is the net present value approach with only one leaf that represents expectations of all stochastic variables, and no incentive to postpone. Adding already one additional leaf converts the problem into real options and might create incentives to postpone investment. Also, note that the number of leaves has differential influence on model outcomes. In particular, it might be cumbersome to stabilize integer variables within a certain range of accuracy. We suggest proceeding as follows: (1) choose the model's "main result variable"; (2) determine an appropriate degree of deviation for this variable; (3) run a sensitivity analysis with an increasing number of leaves and observe the effect on this variable; and (4) stop increasing tree size once the variable stabilizes within the deviation level.

We solve the model described above with stochastic programming using standard Java libraries for Monte Carlo simulations; GAMS 24.3; a tree construction tool SCENRED2 (GAMS, 2015); and an optimization solver, CPLEX (IBM, 2016). The use of Java is mostly motivated by the fact that we store the generated simulations along with the ancestor matrix to describe the node structure efficiently in the proprietary data format GDX (of GAMS) to avoid costly computations (in GAMS). The computational speed can be increased by employing a multi- 
core processor as Mixed Integer Programming (MIP) solvers such as CPLEX efficiently work in parallel. Additional techniques for improving computational efficiency for such large-scale mixed-integer stochastic problems are available (Escudero et al., 2012). The output consists of an optimal distribution of (quasi-) limited resources between available investment options for each node of the reduced scenario tree, considering all the possible future paths and solving hence for both optimal timing and scale of investment (see Section 5 for more details). Various follow-up analyses can be run based on our method. A sensitivity analysis with respect to a stochastic variable is illustrated below; an example of a policy analysis can be found in Spiegel et al. (2018).

\section{Case study: reallocating land to perennial energy crops}

We choose farm-level decisions regarding the adoption, harvest and conversion of perennial crop production in the context of farm constraints and alternative activities. Specifically, we consider investments into short rotation coppice (SRC) poplar production systems under price and opportunity costs uncertainty in Germany; the problem is characterized by limited resources, returns-to-scale, and predefined sizes of available investment options. The main characteristics of the case study are summarized in Table 1.

Table 1 Summary of the main characteristics of the case study.

\section{Characteristics of an actual large-scale investment project \\ Expressed in the case-study via}

Short rotation coppice plantation with initial establishment (can be postponed by four years), intermediate harvests after $2-5$ years

Multi-stage investment option from previous stage (i.e., establishment or harvesting), and final conversion to alternative land use (maximum 20 years' post establishment and exercised only in combination with harvest)

Stochastic component

Biomass price (i.e., price for short rotation coppice output)

Establishment costs, harvest related costs, and final conversion costs. Typically, about

Sunk costs $2 / 3$ of SRC production system costs are associated with the establishment and final conversion such that a large share of costs is sunk. 
Predefined investment sizes

Opportunity costs

Returns-to-scale

Resource endowments

Policy constraints
Predefined land plots for potential conversion to short rotation coppice plantation

Annual production systems, specifically two annual crop options with different inputs (i.e., land and labor) and outputs (i.e., gross margins)

Harvest costs including costs (a) on farm (fixed), (b) per plot (quasi-fixed), and (c) per ton of harvested biomass (variable)

Land and labor: both are assumed to be limited without possibility for expansion

An "Ecological Focus Area" representing 5\% of farmland area must be left set-aside or converted to short rotation coppice plantation (SRC is recognized in the model as equivalent to set-aside land with a coefficient of 0.3 )

Under SRC management, fast-growing trees are harvested, or coppiced, for energy production within relatively short intervals - typically between two and five years if the end product is wood trunk, which is common in Germany; and longer than five years if the end product is wood chips. Harvest means that trees are cut down close to their roots and put out new shoots from their stump afterwards. That allows multiple harvests over a period of up to 20 years. We assume a farmer to stick to one end product (wood trunk) and hence restrict harvesting period by two to five years. Introduction of longer harvesting periods, e.g., for wood chips, would lead to fewer harvestings in total (i.e., max. 2 or 3 in total over 20 years). In order to quantify the effect of different agricultural practices (i.e., introducing an option to change the end product and hence to harvest between two and twenty years), a precise yield function for longer harvesting intervals would be required, which data is not available and goes beyond our expertise.

The application of real options in agricultural economics is rather limited, especially in terms of investment analysis of perennial energy crop production; the dominant approach in the literature is the net present value (Gandorfer et al., 2011; Lothner et al., 1986; Schweier and Becker, 2013; Strauss et al., 1988). The few existing models have either considered perennial energy crop cultivation as a stand-alone investment option (Frey et al., 2013), or (partly) omitted managerial flexibility it allows for (Bartolini and Viaggi, 2012), or both (Musshoff, 2012; Song et al., 2011; Wolbert-Haverkamp and Musshoff, 2014). In particular, ignoring 
alternative land use options is usually motivated by the assumption that perennial energy crops would be introduced on land that was previously set aside (Musshoff, 2012). Yet, this assumption is not plausible due to policy constraints such as the Ecological Focus Area (EFA) coefficient, where perennial energy crops are $1 / 3$ of the one for set-aside land. Hence, perennial energy crops compete with alternative land use options. At the same time, existing real options valuation methods fail to capture complexity of the case study. In fact, if we opt for a binomial (trinomial) scenario tree, we would need to significantly reduce the considered time horizon (24 years), e.g., via aggregating time periods when the orchard is growing and therefore not considering different harvesting periods, as it was done, e.g., in Musshoff (2012). In addition, we would have an exploding scenario tree that would include unrealistic realizations. If we opt for LSMC, the problem would be numerically demanding, since to account for resource endowments and other constraints we would need to solve each Monte Carlo path backwards for each stage, starting from the last one, and each possible level of SRC adoption. We would also have to assume a functional form of the payoff function, in order to run Least Squares regression, while having no solid reference for such an assumption.

Using our method, these restrictive assumptions can be simultaneously relaxed without hampering tractability and computational efficiency. We treat the decisions to invest into a SRC plantation and its subsequent management as a multi-stage real option, where establishment, each intermediate harvest, and final conversion to alternative land uses are the option stages. Due to stage-contingent inter-harvest periods ranging between two and five years and the maximum plantation lifetime, the total number of stages is flexible, not predetermined. As a consequence, the sooner each stage is exercised, the more available stages there are overall. Postponing the harvest and letting plantation to grow leads to higher yields over time. We assume that a farmer can postpone establishment up to four years and that the maximum age of a SRC plantation is twenty years; these assumptions lead to a total modelled time horizon of 24 years. A longer postponement period would add an option value, i.e., incentives to wait, and also increase the overall time horizon; yet, it also provokes discussion on plausible time horizon from farmer's perspective. 


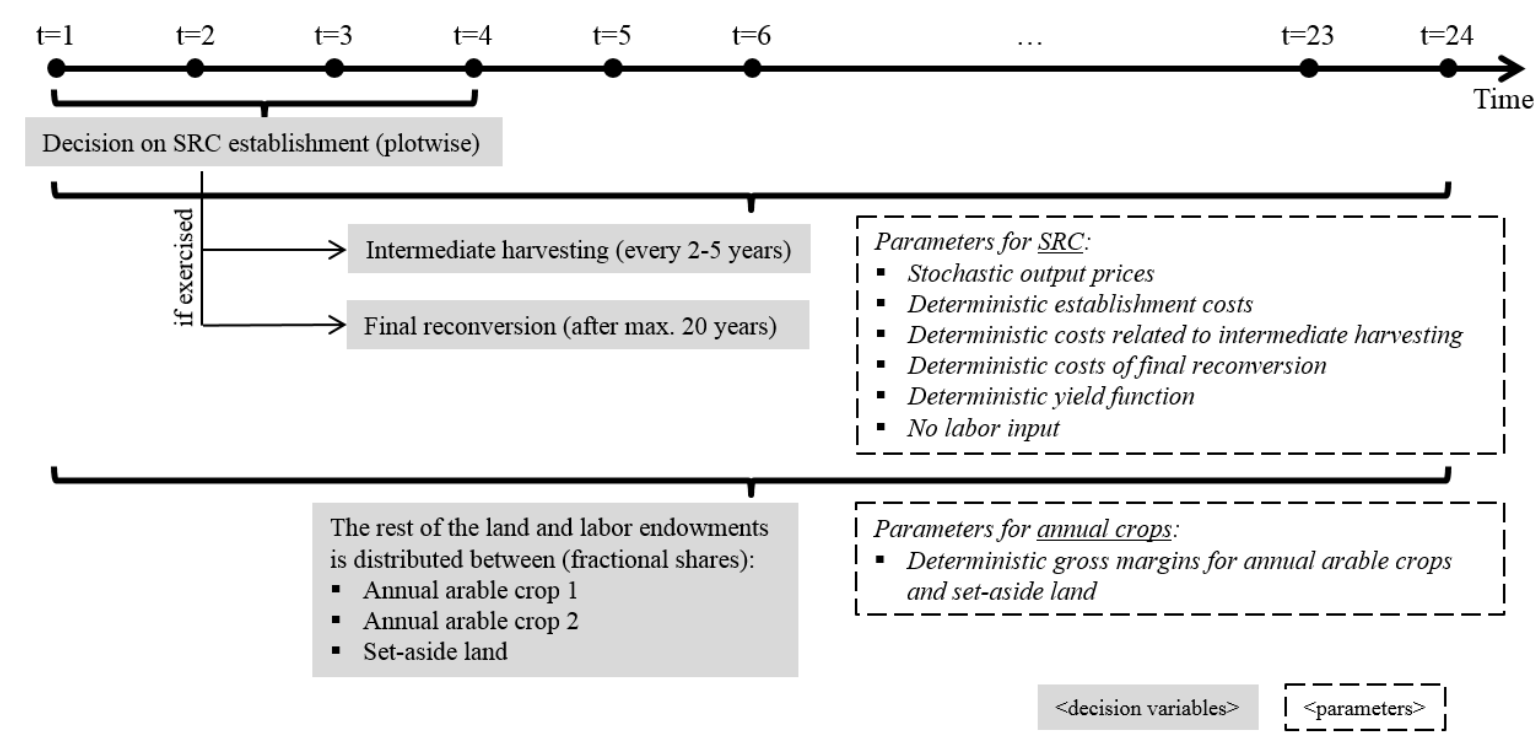

Fig. 3 Graphical representation of the farm-level model. See also Spiegel et al. $(2018,2017)$ for greater detail.

Land that is not converted to SRC is allocated to alternative annual crops and set-aside land as fractional shares. Under annual resolution of the model, there is no incentive to postpone a decision with respect to annual crops. Choosing between SRC and annual crops can be found in the reality, yet these settings also allow for clarity and simplicity in this example, since no other investment with temporal flexibility beyond SRC is involved. In order to model competition for farm resources such as land and labor, we consider two relevant alternative crops for the case study region - winter wheat and winter rapeseed - of which the former is more labor intensive and has a higher gross margin per hectare. Both annual crops are characterized with stochastic gross margins, so that any land distribution among SRC and annual crops would cause stochastic returns. We use the fixed input-output coefficients to depict competition for land and labor resources of farm:

$$
\sum_{c} \bar{a}_{c, i} * L_{t, c} \leq \bar{b}_{t, i} \quad \forall i \quad \forall t
$$

where $i$ represents inputs including land and labor; $c$ includes alternative land use options; $\bar{a}_{c, i}$ denotes fixed input-output coefficients of land uses; $\bar{b}_{t, i}$ describes farm-level resource endowments; and $L_{t, c}$ indicates the area allocated to each land use over years [ha $\left.\mathrm{y}^{-1}\right]$. In Germany, land use competition between SRC and other land uses has been reduced under the European Common Agricultural Policy, which require large arable farms ( $>15$ ha of arable land) to manage $5 \%$ of farmland as "Ecological Focus Areas" (EFA), as a part of the "greening 
measures" of the Common Agricultural Policy, to which SRC partially qualifies (in Germany one unit of land under SRC management is equivalent to 0.3 of an equal area of set-aside for EFA purposes (BMEL, 2015)). In particular, the direct payments to farmers are reduced by $30 \%$, unless certain environmental requirements are fulfilled. In our model, we consider two options to meet the "Ecological Focus Area" requirements: set-aside land with the coefficient of 1.0 and SRC with the coefficient of 0.3 (for a description of other options and the respective coefficients see BMEL (2015)). We also assume that the requirement has to be fulfilled, i.e. receiving reduced direct payments is not an option. Compliance with the 5\% "Ecological Focus Area" land-use requirement is ensured as follows:

$$
L_{t, c=s e t a s i d e}+0.3 * L_{t, c=S R C} \geq 0.05 * \bar{b}_{t, i=\text { land }}
$$

where $L_{t, c}$ represent area under respective crop $c$ over years $\left[\right.$ ha $\left.\mathrm{y}^{-1}\right] ; t$ is the period of analysis $(1,2, \ldots, T)$ with $T$ equal to 24 years in our example; $\bar{b}_{i=\text { land }}$ is the total land endowment [ha $\left.\mathrm{y}^{-1}\right]$.

We consider pre-defined plantation sizes because farmers would typically convert existing plots of some other land use to SRC plantation. Assuming total land endowment of 100 ha, we consider three potentially convertible plot sizes of 10 ha, 20 ha, and 40 ha, providing eight possible plantation size combinations from 0 to 70 ha. Initially four plots and 11 combinations from 0 to 100 ha were assumed, hence covering all available land. Since tests revealed that the optimal total area under SRC to be below 40 ha at any path of the scenario tree, we restrict ourselves to three plots as described in the text in order to decrease the number of variables and gain computational efficiency. This additional constraint is also in line with the reality, as farmers do not convert a substantial part of their farm into SRC. Each plot is characterized by three core decision variables over the simulation horizon (Fig. 3): (1) land-use decisions: whether a plot is used for SRC or one of the three alternative activities; (2) SRC harvesting decisions: whether or not a SRC plot is harvested in the current year; and (3) the decision of whether or not to convert SRC to an alternative land use. Conversion can be exercised only in combination with harvesting, i.e., costs for conversion include harvest and clear-cutting the SRC. Relative to alternative land uses, SRC is characterized by low-input production (Faasch and Patenaude, 2012); establishment and harvesting are usually outsourced to a contractor, minimizing or eliminating the need for on-farm labor (Musshoff, 2012, p. 77). 
The model data are from SRC poplar production systems in northern Germany (federal state Mecklenburg-Western Pomerania) and based on the literature (Table 2). Relative to average conditions in Germany, the region is characterized by low soil quality and precipitation (Table 3 ), and generally low returns from annual crops. The limited productivity of annual crops increases the attractiveness of land-use options such as SRC management. According to Schuler et al. (2014, p. 69), over $90 \%$ of agricultural lands in this region are suitable for SRC.

Table 2 Data and model parameters

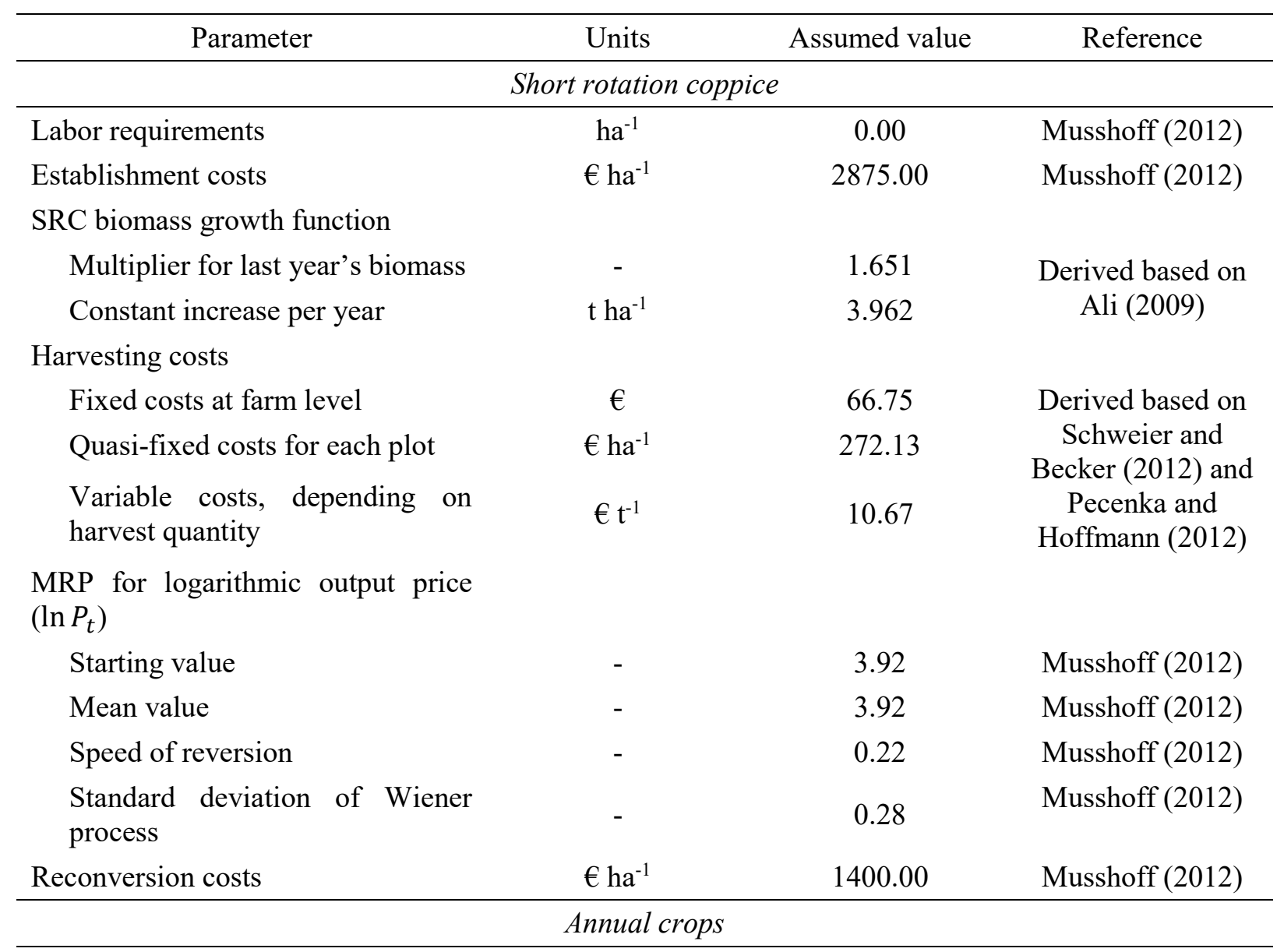

Net annual cash flow from traditional land use

Winter wheat

Winter rapeseed

Set-aside

Labor requirements ${ }^{4}$

Winter wheat

Winter rapeseed

$\begin{array}{ccc}€ \mathrm{ha}^{-1} & 537.15 & \text { CAPRI (2017) } \\ € \mathrm{ha}^{-1} & 460.64 & \text { CAPRI (2017) } \\ € \mathrm{ha}^{-1} & -50.00 & \text { CAPRI (2017) } \\ \mathrm{ha}^{-1} & 5.32 & \text { KTBL (2016) } \\ \mathrm{ha}^{-1} & 4.16 & \text { KTBL (2016) }\end{array}$

\footnotetext{
${ }^{4}$ Only includes field work, excluding work associated with management, which is assumed to be limited per farm and hence has no effect on resource distribution.
} 


\begin{tabular}{lccc}
\multicolumn{1}{c}{ Set-aside } & ha $^{-1}$ & 1.00 & KTBL (2016) \\
\hline Land area & ha & & \\
& & 100.00 & $\begin{array}{c}\text { Own assumptions } \\
\text { based on statistical } \\
\text { data (StAmtMV, } \\
\text { 2016) and } \\
\text { Labor availability }\end{array}$ \\
& - & 455.00 & $\begin{array}{c}\text { rounding for the } \\
\text { sake of } \\
\text { straightforward } \\
\text { interpretation of } \\
\text { results }\end{array}$ \\
Real risk-free discount rate & & Musshoff (2012) \\
\hline
\end{tabular}

Two elements of parameterization deserve further attention. First, we adapt the SRC biomass yield function from Ali (2009):

$$
\begin{gathered}
Y=2.27 *\left(-0.1133 * 10^{-8} * D^{2}+0.254 * 10^{-4} * D+0.028\right) *(1.569 \\
* H I+0.4 * 10^{-3} * P T * S Q I \\
\left.-\frac{23.198 * T e m p}{W}\right)^{\left(0.34 * 10^{-8} * D^{2}-0.501 * 10^{-4} * D+2.614\right)}
\end{gathered}
$$

where $Y$ represents dry matter yields, $D$ is the density of trees per hectare; $H I$ is the intermediate harvesting interval $(2,3,4$, or 5 years); $P T$ is the mean sum of precipitation in May and June (mm); SQI is a soil quality index value; Temp is the mean temperature from April through July $\left({ }^{\circ} \mathrm{C}\right)$; and $W$ represents available ground water capacity $(\mathrm{mm})$. All the variables in Eq. 3, except for intermediate harvesting interval $H I$ (being a decision variable with possible values of 2, 3, 4 , or 5 years), were fixed the levels as presented in Table 3.

Table 3. Parameters of the yield function and assumed values

\begin{tabular}{clll}
\hline Variables & \multicolumn{1}{c}{ Description } & Values & \multicolumn{1}{c}{ References } \\
\hline$D$ & density of trees per hectare & 9,000 & Musshoff (2012) \\
& & & $\begin{array}{l}\text { Based on precipitation recorded for May and June } \\
(1995-2015) \text { in Mecklenburg, Germany } \\
\text { (WetterOnline 2016) }\end{array}$ \\
mean sum of precipitation & 106.27 & & Musshoff (2012)
\end{tabular}

\footnotetext{
${ }^{5}$ Based on the assumption that initially $47.5 \%$ of land area is devoted to winter wheat, $47.5 \%$ to winter rapeseed, and $5 \%$ is set-aside. This composition excludes management and off-farm work; both of which are assumed to be limited at the farm level and hence have no effect on resource distribution.
} 


\begin{tabular}{clcl} 
Temp & $\begin{array}{l}\text { mean temperature from } \\
\text { April through July }\left({ }^{\circ} \mathrm{C}\right)\end{array}$ & 14.51 & $\begin{array}{l}\text { Mean of daily mean temperatures (minimum and } \\
\text { maximum) for April through July (1995-2015) in } \\
\text { Mecklenburg, Germany (WetterOnline 2016) }\end{array}$ \\
& $\begin{array}{l}\text { available ground water } \\
\text { capacity }(\mathrm{mm})\end{array}$ & 220.00 & Musshoff (2012) \\
\hline
\end{tabular}

Eq. 3 combined with values from Table 3 outputted SRC biomass yields as a function of harvesting interval $\mathrm{HI}$, which we fitted to a linear function for biomass stock that depends on previous year's stock (the right hand side part of the Eq. 4). In combination with the harvest decision for the previous year, the SRC biomass yield function provides current SRC yields:

$$
\text { stock }_{t, p}+\text { harvQuant }_{t, p}=\left(1.651 * \text { stock }_{t-1, p}+3.962\right) * S_{p}
$$

where $p$ denotes the land plot index; stock $k_{t, p}$ stays for standing biomass, [in tonnes of dry matter yields per year $\left.\left(\mathrm{t}^{-1}\right)\right]$; harvQuant ${ }_{t, p}$ stays for the amount of biomass harvested $\left[\mathrm{t}^{-1}\right]$;

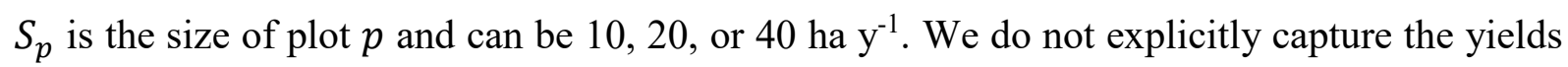
of annual crops, considering deterministic net annual cash flows per hectare of annual crops that consist of respective yields multiplied by the farm-gate price minus all the associated costs (see Table 2 for the respective parameters). Also, set-aside land is characterized with a deterministic net annual cash flow per hectare. Our method allows further elaboration with respect to yield functions of SRC biomass and annual crops, for instance, by introducing uncertainty related to climate change or other environmental risks. For the sake of simplicity, we leave these potential model improvements for future research.

Revenues from an SRC plantation are linked to harvest decisions, which are based on the interactions among SRC biomass growth and harvest cost functions. Harvesting the standing biomass only partly is not considered feasible; therefore, an additional equation ensures that standing stock from the previous year is completely removed when harvesting. Eq. 4 hence yields at the end of year $t$ either a biomass stock, which captures the additional growth in that year given last year's stock, or a zero. In the latter case biomass stock is harvested at the end of 
year $t$. The linkage between the decision to harvest in a specific year and harvested biomass is reflected by a binary indicator inequality and a maximal bound:

$$
\begin{gathered}
\operatorname{harvQuant}_{t, p} \geq \text { harvest }_{t, p} * \overline{\text { minHarvQuant }}_{p} \\
\text { harvQuant }_{t, p} \leq \overline{\text { maxHarvQuant }}_{p}
\end{gathered}
$$

where harvest $_{t, p}$ indicates whether a plot is harvested $(=1)$ or not $(=0) ; \overline{\text { minHarvQuant }}_{p}$ is a constant that defines the minimal harvest quantity $\left[\mathrm{t}^{-1}\right]$; and $\overline{\text { maxHarvQuant }}_{p}$ is a constant that defines the maximal harvest quantity $\left[\mathrm{t} \mathrm{y}^{-1}\right]$. Minimal and maximal harvest quantities are defined after the plantation has grown for a number of years ( 2 and 5 years respectively in our case) and can be calculated using the SRC biomass growth function (Eq. 4). These data can be introduced in the two equations above to ensure the minimal and maximal waiting times between harvests.

Second, based on Schweier and Becker (2012) and Pecenka and Hoffmann (2012) we derive harvesting cost for SRC biomass separated by (a) costs at farm level (fixed) and (b) per plot (quasi-fixed), plus (c) costs per metric ton of harvested SRC biomass (variable) in order to consider the economy of scale. The harvest cost function considers transaction costs for outsourcing labor, field-level transport costs, harvest costs, post-harvest fertilization costs, and costs of drying and storing harvested biomass and is defined as follows:

$$
\text { TotalHarvCost }_{t}=\sum_{p}\left[66.75+272.13 * S_{p}+10.67 * \text { harvQuant }_{t, p}\right]
$$

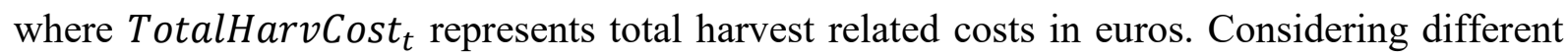
harvest intervals allows the plantation to store biomass, such that temporal arbitrage can be applied: a farmer might allow trees to continue growing if biomass prices are low and expected to increase in the future, increasing future harvestable volumes. Moreover, since we specify fixed and quasi-fixed harvest costs, the total harvest cost per ton of dry matter declines over time elapsed since establishment or the preceding harvest; between two and five year intervals are considered in the case study (Table 4). 
Table 4 SRC biomass yields and harvest costs based on harvest interval and land area. Source: calculated using Eq. 4 for different land areas and harvest intervals

\begin{tabular}{|c|c|c|c|c|c|}
\hline & \multirow{2}{*}{$\begin{array}{c}\text { Land area } \\
\text { under SRC } \\
\text { (ha) }\end{array}$} & \multicolumn{4}{|c|}{ Harvest interval (years) } \\
\hline & & 2 & 3 & 4 & 5 \\
\hline $\begin{array}{l}\text { Dry matter yields } \\
\qquad\left(\mathrm{t} \mathrm{ha}^{-1}\right)\end{array}$ & any & 10.503 & 21.302 & 39.133 & 68.571 \\
\hline \multirow{4}{*}{$\begin{array}{c}\text { Harvest costs } \\
\left(€ \mathrm{ha}^{-1}\right) \\
\text { In parentheses are } \\
\text { harvest costs per } \\
\text { tonne of dry matter }(€ \\
\left.\mathrm{t}^{-1}\right)\end{array}$} & 1 & $\begin{array}{l}450.95 \\
(42.94)\end{array}$ & $\begin{array}{l}566.17 \\
(26.58)\end{array}$ & $\begin{array}{l}756.43 \\
(19.33)\end{array}$ & $\begin{array}{c}1,070.53 \\
(15.61)\end{array}$ \\
\hline & 10 & $\begin{array}{l}390.87 \\
(37.22)\end{array}$ & $\begin{array}{l}506.10 \\
(23.76)\end{array}$ & $\begin{array}{l}696.35 \\
(17.79)\end{array}$ & $\begin{array}{c}1,010.46 \\
(14.74)\end{array}$ \\
\hline & 30 & $\begin{array}{l}386.42 \\
(36.79)\end{array}$ & $\begin{array}{l}501.65 \\
(23.55)\end{array}$ & $\begin{array}{l}691.90 \\
(17.68)\end{array}$ & $\begin{array}{c}1,006.01 \\
(14.67)\end{array}$ \\
\hline & 50 & $\begin{array}{l}385.53 \\
(36.71)\end{array}$ & $\begin{array}{l}500.76 \\
(23.51)\end{array}$ & $\begin{array}{l}691.01 \\
(17.66)\end{array}$ & $\begin{array}{c}1,005.12 \\
(14.66)\end{array}$ \\
\hline
\end{tabular}

The objective function is defined as follows:

$$
\begin{aligned}
N P V=\sum_{t=1}^{T}\left[\sum_{c}\right. & \frac{G M_{t, c} * L_{t, c}}{(1+i)^{t}} \\
& +\sum_{p} \frac{P_{t}^{S R C} * \text { harvQuant }_{t, p}-\text { iniCost }_{t, p}-\text { reconvCost }_{t, p}}{(1+i)^{t}} \\
& \left.-\frac{\text { TotalHarvCost }_{t}}{(1+i)^{t}}\right]
\end{aligned}
$$

where $G M_{t, c}$ stays for gross margin of a land use option $c$ in time period $t\left[€ \mathrm{ha}^{-1} \mathrm{y}^{-1}\right] ; L_{t, c}$ stays for fractional land area dedicated to a land use option $c$ in time period $t$ [ha $\left.\mathrm{y}^{-1}\right]$; iniCost $_{t, p}$ represents the actual set-up costs per plot $\left[€ \mathrm{y}^{-1}\right]$; reconv Cost $_{t, p}$ represents actual reconversion costs per plot $\left[€ \mathrm{y}^{-1}\right] ; i$ is an annual risk-free discount rate of $3.87\left[\% \mathrm{y}^{-1}\right]$. The net present value defined in Eq. 8 is maximized subject to two constraints: (i) farm resource endowments including land and labor (Eq. 1); and (ii) policy constraint that includes the 5\% EFA land-use requirement (Eq. 2).

After setting up the mixed integer programming model that maximizes the net present value (Fig.3), uncertainties are introduced into the model. We assume that during the lifetime of a 
plantation, farmers face a SRC biomass price uncertainty. While the same might hold true for alternative land uses, the ability to adjust the land use composition and management intensity on an annual basis might substantially reduce subjective uncertainty for individual farmers (Di Falco and Perrings, 2003). In particular, we assume a natural logarithm for the SRC output price to follow a mean-reverting process (MRP), specifically an Ornstein-Uhlenbeck process (de Oliveira et al., 2014; Musshoff, 2012):

$$
d \hat{P}_{t}=\mu_{S R C}\left(\theta_{S R C}-\hat{P}_{t}\right) d t+\sigma_{S R C} d W_{t}^{S R C}
$$

where $t$ is the time period; $\hat{P}_{t}$ is the natural logarithm of price of SRC biomass; $\mu_{S R C}$ is the speed of reversion of the stochastic process for SRC biomass price; $\theta_{S R C}$ is the long-term logarithmic average price of SRC biomass; $\sigma_{S R C}$ is the standard deviation of logarithmic SRC biomass price; $d W_{t}^{S R C}$ is the standard Brownian motion. The choice of stochastic process is motivated by the assumption that the farmer is a price-taker in a market where the price fluctuates around a constant long-term level due to market forces, for instance, under the assumption of no monopolistic power (Metcalf and Hassett 1995) and/or of constant technology (Song, Zhao, and Swinton 2011). An MRP process is also assumed for SRC biomass price in the previous literature (Musshoff 2012; de Oliveira et al. 2014). See Spiegel et al. $(2018,2017)$ for introduction of multiple (correlated) stochastic processes. After 10,000 Monte Carlo simulation runs for output prices, we apply scenario tree reduction. To determine the optimal number of leaves, we choose the expected area under SRC as the main result and stabilize it within $10 \%$ of the expected area under SRC under 500 leaves. We found 100 leaves to be a 
good tradeoff between accuracy and speed. The objective function defined in Eq. 8 is modified as follows:

$$
\begin{aligned}
& E[N P V]=\sum_{\text {path }}\left[\pi_{\text {path }} * N P V_{\text {path }}\right] \\
& =\sum_{\text {path }}\left[\pi_{\text {path }}\right. \\
& * \sum_{t=1}^{T}\left[\sum_{c} \frac{G M_{(t, n), c} * L_{(t, n), c}}{(1+i)^{t}}\right. \\
& +\sum_{p} \frac{P_{(t, n)}^{S R C} * \operatorname{harvQuant}_{(t, n), p}-\text { iniCost }_{(t, n), p}-\operatorname{reconv} \operatorname{Cost}_{(t, n), p}}{(1+i)^{t}} \\
& -\frac{\left.\operatorname{TotalHarvCost}_{(t, n)}\right]}{\left.(1+i)^{t}\right]}
\end{aligned}
$$

where $E[\cdot]$ represents expectation operator; $\pi_{\text {path }}$ stays for probability of each path, where $\sum_{\text {path }} \pi_{\text {path }}=1$; and $(t, n)$ is a combination of time and node of the scenario tree assigned to each path. The constraints are modified accordingly. Note that assuming a risk-averse farmer would require applying different discount rates to the cash flows from SRC (i.e., stochastic) and from alternative agriculture (i.e., risk-free) (e.g. see Finger (2016) for further details). For the sake of clarity in our analysis, we restrict ourselves to a risk-neutral decision and hence apply the market-based risk-free discount rate to all cash flows.

We run two types of sensitivity analyses. First, we quantify the effect of introducing temporal flexibility into the model by comparing the results under the baseline real options settings as presented above and the results under the net present value approach. For the latter, we impose in the model that the farmer makes decisions on establishment, harvesting and conversion immediately based on expected biomass output price, i.e., we switch from a stochastic to deterministic model. For consistency, we use the same Monte Carlo draws and the same reduced scenario tree for both real options and net present value approaches. We also compare our results with results obtained with a less complex model applied to the same case study by Musshoff (2012). In particular, the model is also based on the real options approach, but ignores economy of scale, considers SRC as a stand-alone option, and fixes the harvesting intervals at three years. Second, we analyze the influence of the observed biomass price on farmer's 
decision making. We shift the constructed scenario tree up and down in parallel keeping all the other parameters constant. In other words, the value in each node of the constructed scenario tree is multiplied by a certain coefficient, while deterministic parameters of the model remain at their baseline levels. Spiegel et al. (2018) provide a comprehensive policy analysis, as well as illustrate introducing multiple correlated stochastic variables. The model, including a Graphical User Interface that allows straightforward changes to the initial parameters, and all related documentation are available in Spiegel et al. (2017).

\section{Empirical results and related discussion}

Under the baseline SRC output price scenario (i.e., observing in year one a SRC biomass output price of $50 € \mathrm{t}^{-1}$ ), the farmer waits and establishes SRC in the second or third years with a probability of $23 \%$, and in the fourth year - with a probability of $41 \%$, depending on the SRC biomass price development in the respective years (Fig. 4). There is a chance of $13 \%(=100 \%$ (in year one) $-23 \%$ (in year two) $-23 \%$ (in year three) $-41 \%$ (in year four) that SRC would never be established, if the SRC biomass price hits the lowest paths of the scenario tree. A breakdown by investment scale is beyond the scope of the information presented in Fig. 4: if an SRC plantation is established in the second year under the baseline scenario, $87 \%$ of the SRC plantations would be 10 ha and the remaining 13\% would be 20 ha, depending on the observed SRC biomass price in $\mathrm{t}=2$. The expected net present value of these investments is $75,743.89 €$.

We now compare these results with the optimal behavior produced by less complex models. Assuming no temporal flexibility, the model suggests to immediately convert 10 ha into SRC at the baseline observed biomass price $\left(50 € \mathrm{t}^{-1}\right)$ and estimates the optimized expected net present value at $58,667.85 €$. Comparing this value with the optimized expected net present value under real options approach $(75,743.89 €)$ means that the value of waiting is equal to $17,076.04 €$. The positive option value for postponing SRC adoption is in line with the observed reluctance of farmers in Germany to adopt SRC under current prices (Allen et al., 2014; Bemmann and Knust, 2010). To this end, implementing real options instead of widely used net present value approach led to a different optimal decision (i.e., wait instead of invest immediately). Yet, a different approach is not the only reason for improving the results. For instance, Musshoff (2012) also applied real options approach to the same case study, used the same parameters as we do (Table 2), but made some restrictive assumptions, such as ignoring 
economy of scale, considering SRC as a stand-alone option, and fixing the harvesting intervals at three years. Such model suggests that immediate establishment of SRC is profitable despite possibility to postpone, which contradicts the observed reluctance towards SRC. We presume that our model better explains the observed behavior due to consideration of more aspects of a real-world investment context, such as full managerial flexibility in SRC cultivation and alternative land uses that compete for resources. Since the model designed by Musshoff (2012) is designed on per-hectare-basis and not at farm level, it does not consider the expected scale of SRC introduction, which is crucial when evaluating aggregate economic and environmental effects of SRC.

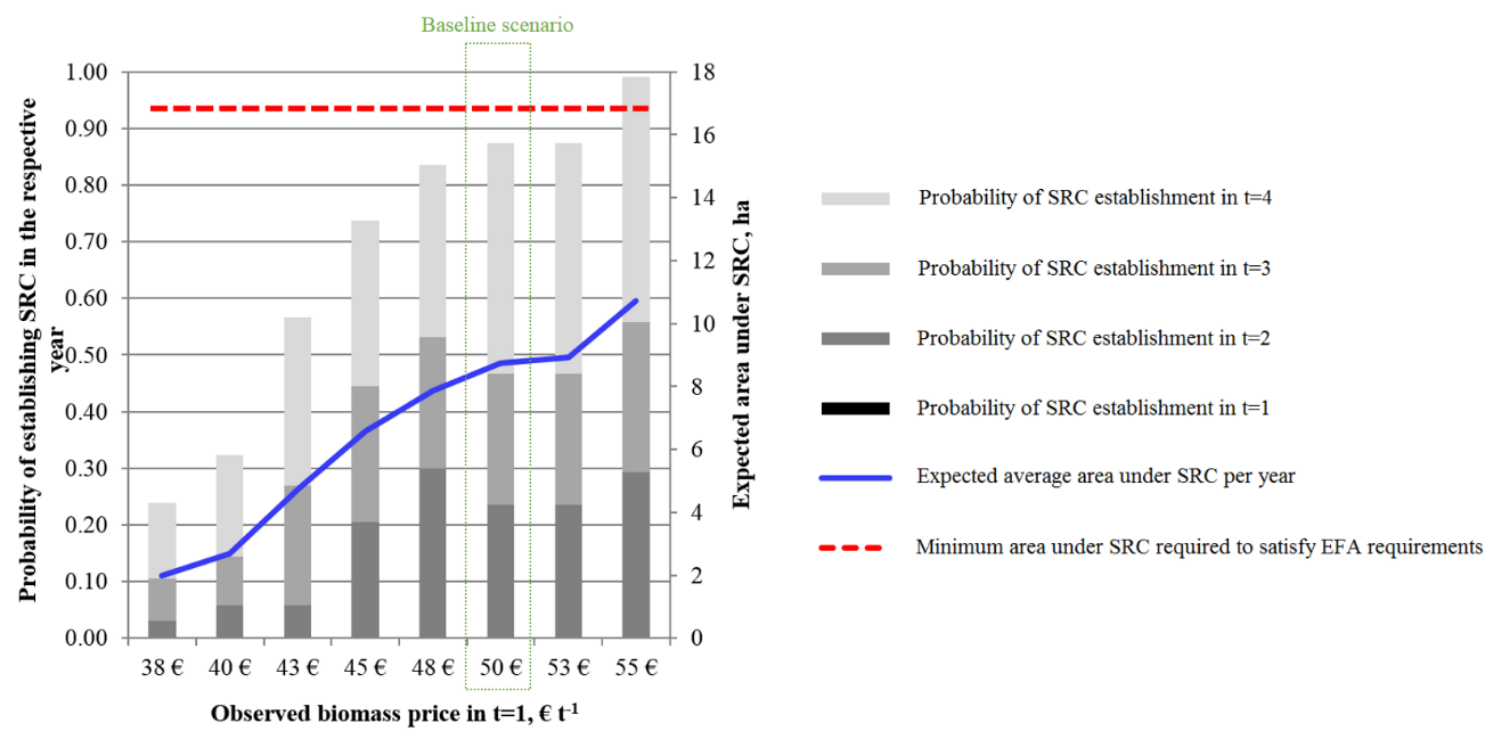

Fig. 4 Sensitivity analysis with respect to biomass output price for short rotation coppice (SRC) establishment decisions with temporal flexibility. Note: the interrupted red line is on the level of 17 ha, which is $5 \%$ of the total area of 100 ha if the coefficient 0.3 is applied ( $17 \mathrm{ha} * 0.3 \approx 5 \mathrm{ha}$ ).

Improved results are not the only empirical advantage of our method. Our method also advances at revealing additional incentives and driving forces that is illustrated below. The results of the sensitivity analysis with respect to the observed biomass price (i.e., the starting value of the scenario tree) confirm that the (expected) area under SRC increases as biomass prices increase (blue solid line in Fig. 4), and the chance of an earlier establishment of SRC is higher. Increasing the observed biomass price further, e.g., going beyond Fig. 4, would produce a trigger price, i.e., a price level at which the option value of waiting diminishes and it is optimal to adopt SRC immediately. The same sensitivity analysis can be performed for every stage of investment, such as for harvest and land use conversion decisions at any time point. The EFA requirements are not fulfilled with SRC only under the presented scenarios. The interrupted red line in Fig. 4 
indicates the area of SRC needed to satisfy EFA requirements and is always above the expected area under SRC. This reveals that the policy measure is not fully exploited; under the scenarios considered SRC is not competitive with alternative land uses. Ignoring policy measures and opportunity costs would have obscured this result. According to the concept of the future Common Agricultural Policy in the EU, Member States are expected to have more freedom in setting up weighting factors for EFA requirements (EC, 2019). In this regard, our method is a powerful tool that allows informing policy makers about true (dis)incentives of currently implemented environmental policies, as well as designing and comparing potential policy instruments.

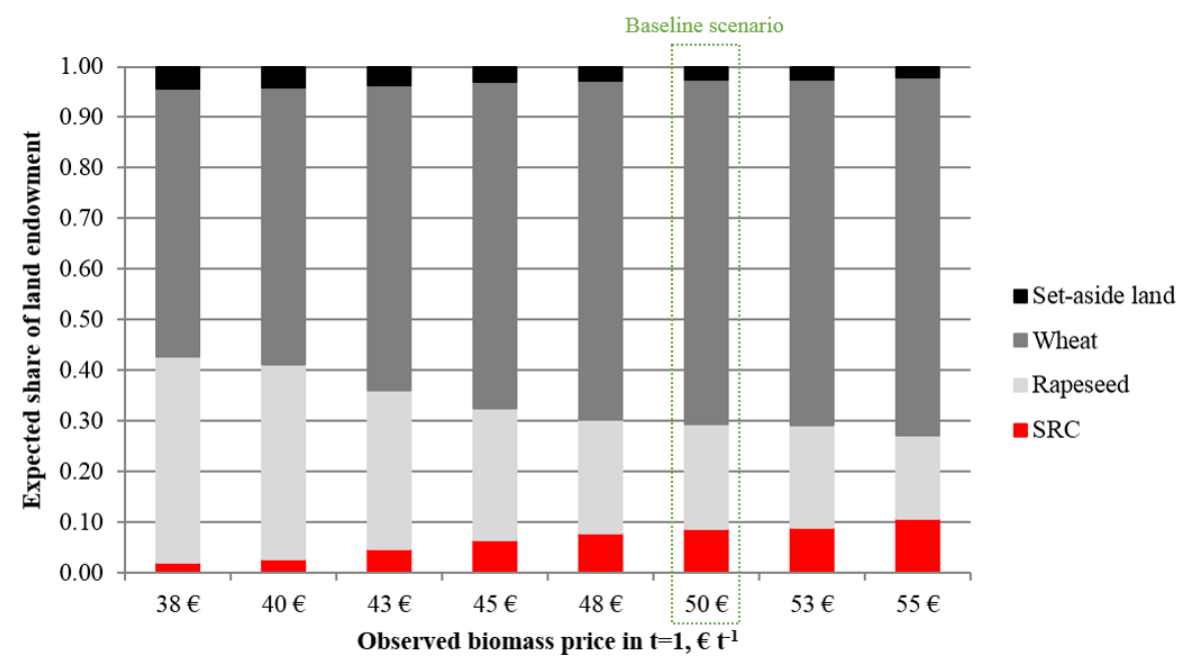

Fig. 5 Expected land distribution (annual mean) between alternative farm activities under different starting (observed) values of the scenario tree assuming temporal flexibility. Note: although SRC is expected to be implemented (e.g., under baseline conditions when observed biomass price is equal to $50 € \mathrm{t}^{-1}$ ), it is not established immediately.

The relative competitiveness of SRC management in our analysis considers redistribution of resources among alternative land uses as an investment consequence. On the one hand, more land under SRC is required for EFA compared to set-asides, as one hectare of SRC is equivalent to 0.3 ha of set aside for EFA purposes. On the other hand, labor requirements of SRC are lower than for alternative land uses. Thus, converting area under productive land uses to SRC allows increasing the labor share for more intensively managed crops with a higher gross margin per hectare (wheat) on the remaining farm area, which dampens the impact of competition for land. This effect is illustrated in Fig. 5. Increasing the biomass price leads to an increase in the expected area under SRC; yet it also leads to redistribution of resources among all activities of the farm. A similar result can be found if we assume that any freed labor is employed off-farm. 
Observing this additional incentives for investing is only possible by taking into account alternatives (i.e. competing activities), policy measures and constraints.

For clarity, we presented a simplified model that can be improved by adding more alternatives and constraints. Multiple uncertainties, including mutual correlation, can be assumed with the scenario tree characterized by a vector of simulated values in each node (Spiegel et al., 2018). Alternatively, several stochastic parameters can be combined into a single composite uncertainty (Bartolini and Viaggi, 2012; Beraldi et al., 2013; Flaten and Lien, 2007). Furthermore, several investment options with temporal and spatial flexibility can be evaluated and compared, e.g., a choice between several perennial crops with each being able to be introduced, harvested and clear-cut now or later in the future. Risk preferences can also be considered; our method allows the assumption of any risk attitude. If risk preferences are considered, a risk analysis can be conducted. Investment triggers can be determined by conducting sensitivity analyses with respect to any model parameter as a potential trigger. Modifying the respective parameter stepwise would determine intervals within which the decision changes to invest immediately, defining the trigger within this interval. The smaller the sensitivity analysis steps, the narrower the range that encompasses the investment trigger. Our method allows for stepwise relaxation of assumptions and hence quantifying their influence on optimal behavior. A comprehensive policy analysis can be performed, either for measures that directly affect investment options or the alternatives, resource endowments, and/or other constraints (Spiegel et al., 2018). Such analyses would reveal both direct and indirect effects of policy measures due to resource redistribution among alternatives and other management changes.

\section{Implications and further research of the proposed method}

The here developed methodological approach particularly advances in straightforward conversion of existing programming applications based on the net present value approach into real options framework, as well as in introducing more complex and realistic settings into existing real options models. Below, we comment on the main conversion options (A, B, and C on Fig. 6 and Table 6) for so-called "basic model" that implies investing now or never, considers investment option as standing alone, operates in relative terms, but relies on a complex scenario tree. If uncertainty is captured differently, we describe the main ways to transform to a complex scenario tree (I and II on Table 5 and Fig. 6). Combinations of conversion options, i.e. A and B, $\mathrm{A}$ and $\mathrm{C}, \mathrm{B}$ and $\mathrm{C}$, as well as $\mathrm{A}$ and $\mathrm{B}$ and $\mathrm{C}$, are also possible. 
A complex scenario tree (i) better captures the reality due to an appropriate underlying distribution; (ii) is more flexible due to controlled number of leaves and the range of simulated values; and (iii) keeps the transparency and intuitiveness of a binomial scenario tree. Table 5 captures two major alternatives to a complex scenario tree - a binomial (trinomial) scenario tree or lattice and a distribution - and describes how to use our method and introduce a complex scenario tree.

Table 5 Introducing a complex scenario tree into existing models step-by-step

\begin{tabular}{|c|c|c|}
\hline & $\begin{array}{l}\text { Uncertainty in the initial } \\
\text { model }\end{array}$ & Steps to transform to complex scenario tree \\
\hline $\mathbf{I}$ & $\begin{array}{l}\text { Binomial (trinomial) scenario } \\
\text { tree or lattice }\end{array}$ & $\begin{array}{l}\text { 1. Find an appropriate distribution for all the } \\
\text { stochastic variables; also consider possible } \\
\text { correlation between them; } \\
\text { 2. Run Monte Carlo simulation for all the } \\
\text { stochastic variables; } \\
\text { 3. Apply a scenario tree reduction technique to } \\
\text { Monte Carlo draws, pre-determining the } \\
\text { desired number of final leaves in the tree; } \\
\text { In order to select an optimal number of final leaves: } \\
\text { 4. Choose the "main result" of the model and its } \\
\text { appropriate degree of deviation; } \\
\text { 5. Select a relatively low number of final leaves } \\
\text { and run scenario reduction; run the model; } \\
\text { 6. Step-by-step increase the number of final } \\
\text { leaves in the reduced scenario tree, re-run the } \\
\text { model and observe how the "main result" } \\
\text { changes; } \\
\text { 7. Stop increasing the number of leaves once the } \\
\text { "main result" stabilizes within the allowed } \\
\text { deviation range. }\end{array}$ \\
\hline
\end{tabular}

II Distribution or stochastic See I starting from the step 2.
process 

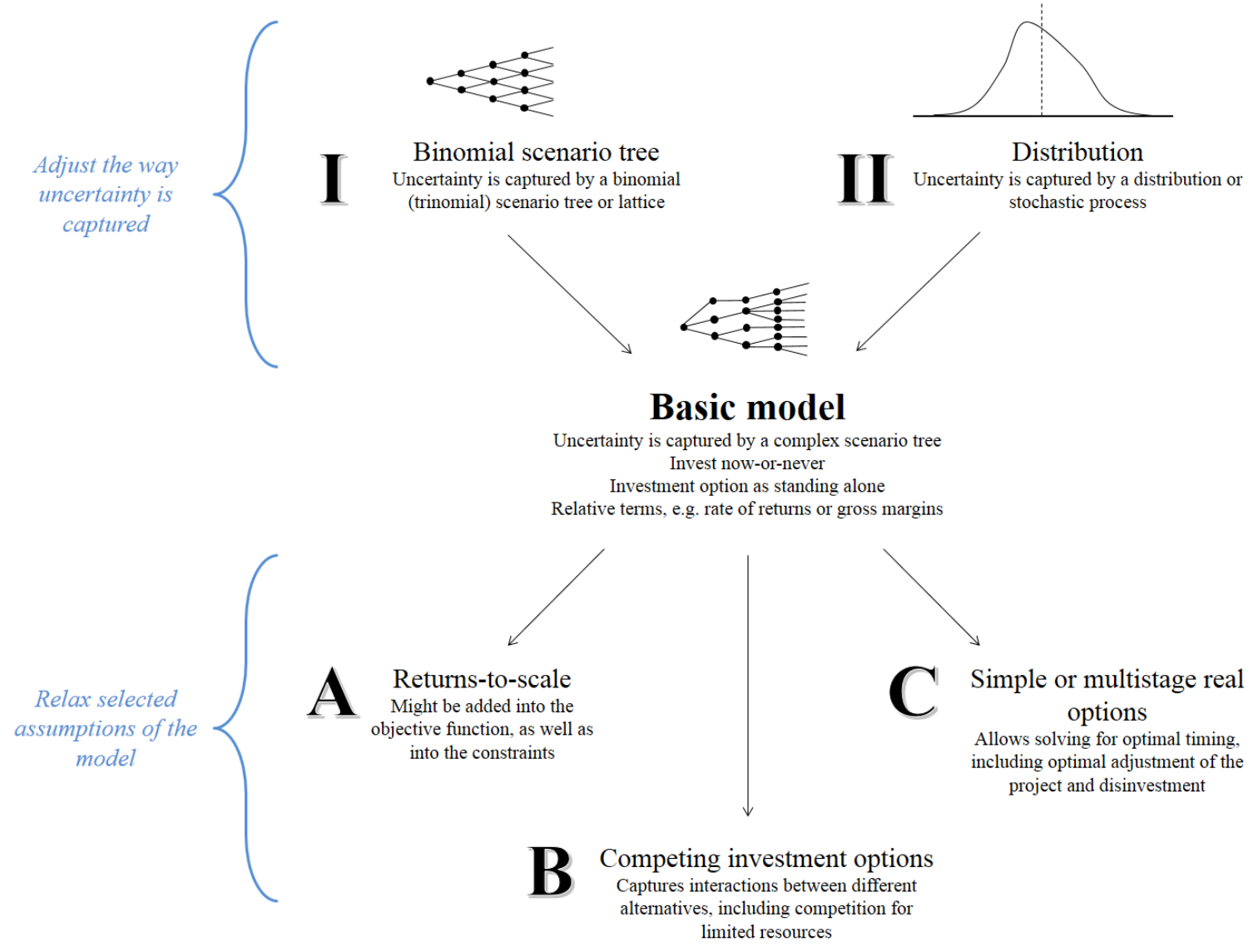

Fig. 6 Possible transformation of existing models for investment analysis based on the net present value using the method developed and illustrated in the paper

Introducing complexity into a model reflects the reality and the pursued research objective. Yet, if higher complexity is intended, our method allows its straightforward introduction. Table 6 summarizes the major peculiarities.

Table 6 Peculiarities of introducing complexity into existing models for investment analysis based on the net present value using the method developed and illustrated in the paper

\section{Introducing ... Peculiarities}

A Returns-to-scale Introducing returns-to-scale requires the model to operate with absolute terms, e.g. maximizing the total net present value instead of rate of return; so, the model might need to be adjusted accordingly.

Returns-to-scale might be introduced into the objective function, as well as into the constraints, e.g. a policy requirement. 
Returns-to-scale might be additionally specified with using investment options of pre-defined sizes (introduced into the model via binary variables)

\section{B Competing investment options \\ Competing investment options imply at least one (quasi)fixed resource or another constraint, e.g. political regulation, that restricts exercising all available investment options; hence, one or several additional constraints might be required. \\ Competing investment options are usually introduced via opportunity costs. \\ There are two approaches generally available: \\ - "either-or" meaning that exercising one investment options excludes exercising the others; this can be modelled via one or several binary variables; \\ - "portfolio" meaning that all investment options might be exercised optimizing their shares in the overall portfolio.}

$\begin{array}{llr}\text { C } & \begin{array}{l}\text { Simple } \\ \text { multistage } \\ \text { options }\end{array} & \text { real } \\ & \end{array}$

Converting a model based on the net present value approach into real options implies solving not only for the optimal scale of investment, but also for optimal timing. Multistage real options allow adjustment of investment based on observed states-ofnature, including expanding and earlier disinvestment.

There are three conditions that should be jointly present in order to create incentives to postpone investments (make sure all three are introduced into the model when converting to real options):

- Possibility to postpone;

- Uncertainty;

- (Partly) sunk costs of investments.

Converting to real options and hence allowing to postpone investment decision would require extending the planning horizon accordingly.

Our method offers multiple methodological advances: using any of the existing methods for illustrative case study would have required making additional restrictive assumptions. The proposed combination of Monte Carlo scenarios and a scenario tree reduction technique overcomes the curse of dimensionality of a binomial (trinomial) scenario tree. The constructed asymmetric scenario tree reflects the underlying distribution, while values are not exploding and the number of leaves is restricted. In contrast to Least Squares Monte Carlo simulation, our method can be applied efficiently to problems of greater complexity. Once resource 
endowments and other constraints are considered the Least Squares Monte Carlo simulation requires a numerical method to solve each Monte Carlo path backwards for each stage, starting from the last one. If the size of the investment project is a decision variable, the Least Squares Monte Carlo simulation requires an additional sensitivity analysis with respect to project size. Generating payoffs for all potential combinations of exercising time points and Monte Carlo runs can be numerically demanding with a programming approach. We find it more straightforward to use stochastic programming directly. Instead of approximating the payoff matrix with a regression function as in Least Squares Monte Carlo simulation, we approximate the Monte Carlo fan based on tree reduction, which is more transparent than Least Squares Monte Carlo simulation. Furthermore, as our case study demonstrates, the method is rather general. It is able to value complex multi-stage options, such as choosing the best combination from a portfolio of different investments that interact, or problems where the number of stages is not pre-determined. There are no restrictive methodological requirements associated with our method. Indeed, any underlying stochastic process can be assumed as long as it is possible to run Monte Carlo simulations and construct a reduced scenario tree. The number of stages is not limited either, unless the relationships between stages cannot be captured with equations. The time horizon is a model parameter and its choice is not restricted. Our method is suitable for comprehensive sensitivity, policy and risk analyses, while representing outcomes in a transparent and intuitive manner.

There are four issues that deserve additional attention. First, an exploding stochastic process cannot be assumed, since a Monte Carlo simulation might quickly lead to unrealistic values. For instance, both a Geometric Brownian Motion and an Arithmetic Brownian Motioncommon assumptions used in the literature for estimating stochastic biomass price (Di Corato et al., 2013; Kallio et al., 2012) — explode by simulating over multiple time periods. Since such simulation values are not plausible, this limitation refers to the assumption itself, rather than the method. Another issue that requires further research is the choice of the number of leaves. As mentioned above, there is no well-established procedure to determine the "optimal" size of the reduced tree. Next, if applying a risk-adjusted discount rate to a scenario tree, it should differ from the risk-adjusted discount rate applied to the underlying asset, because a tree does not correctly represent the underlying volatility (Lander and Pinches, 1998, p. 553). In addition, trees are characterized by decreasing uncertainty approaching the leaves. Therefore, further research could explore methods for determining the appropriate risk-adjusted discount rate for a scenario tree. Finally, introducing complexity and relaxing assumptions of a model usually 
require additional data, which in turn might hamper application of our method. Data availability is crucial, since the method and resulting model have no value added if required data is not available or not reliable.

\section{Conclusion}

This paper proposes a new method which extends the widely applied linear programming approach, for instance used in many bio-economic farm-scale models, to determine simultaneously optimal investment and management decisions and their impacts on environmental impacts. It inherits from the programing approach the possibility to address simultaneously characteristics, such as returns-to-scale, indivisibilities, quasi-fixed resources or multiple competing uses of assets, and adds two new aspects. Firstly, it explicitly models that decision makers might rather wait to learn more about the future and thus are reluctant to invest. The risky future might, e.g., relate to future prices of the investment good or of relevant policies. Secondly, it considers that investment and management plans might be revised in the future depending on how markets and policies evolve. The proposed method thus allows an improved assessment of policies and their environmental impacts where a long-term investment perspective is appropriate.

We apply this approach to analyze the probability of scale and timing of setting up a SRC plantation as an example for the transition towards low-input perennial biomass energy production systems. Such plantations have been found to have multiple environmental advantages compared to biomass energy from conventional arable field crops. We find in our case study that the optimal scale of such investments is quite limited. Furthermore, model results suggest that investors are likely to postpone the investment for some years. Both findings fit the observed reluctance towards SRC and contradict previous analyses with simpler models that claimed such plantations to be profitable immediately. The case study thus underlines the usefulness of the method.

\section{Funding}

This research did not receive any specific grant from funding agencies in the public, commercial, or not-for-profit sectors. 


\section{References}

Abadie, L.M., Chamorro, J.M., 2009. Monte Carlo valuation of natural gas investments. Rev. Financ. Econ. 18, 10-22. https://doi.org/10.1016/j.rfe.2008.10.002

Adams, P.W.R., Lindegaard, K., 2016. A critical appraisal of the effectiveness of UK perennial energy crops policy since 1990. Renew. Sustain. Energy Rev. 55, 188-202. https://doi.org/10.1016/j.rser.2015.10.126

Ali, W., 2009. Modelling of Biomass Production Potential of Poplar in Short Rotation Plantations on Agricultural Lands of Saxony, Germany. Technische Universität Dresden, Dresden, Germany.

Allen, B., Kretschmer, B., Baldock, D., Menadue, H., Nanni, S., Tucker, G., 2014. Space for Energy Crops - Assessing the Potential Contribution to Europe's Energy Future. Institute for European Environmental Policy.

Alonso-Ayuso, A., Carvallo, F., Escudero, L.F., Guignard, M., Pi, J., Puranmalka, R., Weintraub, A., 2014. Medium range optimization of copper extraction planning under uncertainty in future copper prices. Eur. J. Oper. Res. 233, 711-726. https://doi.org/10.1016/j.ejor.2013.08.048

Bartolini, F., Viaggi, D., 2012. An analysis of policy scenario effects on the adoption of energy production on the farm: A case study in Emilia-Romagna (Italy). Energy Policy, Renewable Energy in China 51, 454-464. https://doi.org/10.1016/j.enpol.2012.08.043

Bemmann, A., Knust, C., 2010. Kurzumbetriebsplantagen in Deutschland und europäische Perspektiven. Weißensee Verlag, Berlin, Germany.

Beraldi, P., Violi, A., Simone, F.D., Costabile, M., Massabò, I., Russo, E., 2013. A multistage stochastic programming approach for capital budgeting problems under uncertainty. IMA J. Manag. Math. 24, 89-110. https://doi.org/10.1093/imaman/dps018

Black, F., Scholes, M., 1973. The Pricing of Options and Corporate Liabilities. J. Polit. Econ. $81,637-654$.

Bouchard, B., Warin, X., 2012. Monte-Carlo Valuation of American Options: Facts and New Algorithms to Improve Existing Methods, in: Carmona, R.A., Moral, P.D., Hu, P., Oudjane, N. (Eds.), Numerical Methods in Finance, Springer Proceedings in Mathematics. Springer Berlin Heidelberg, pp. 215-255. https://doi.org/10.1007/978-3642-25746-9_7

Boyle, P.P., 1977. Options: A Monte Carlo approach. J. Financ. Econ. 4, 323-338. https://doi.org/10.1016/0304-405X(77)90005-8 
Brandão, L.E., Dyer, J.S., 2005. Decision Analysis and Real Options: A Discrete Time Approach to Real Option Valuation. Ann. Oper. Res. 135, 21-39. https://doi.org/10.1007/s10479-005-6233-9

Brandes, W., Budde, H.-J., Sperling, E., 1980. A computerised planning method for risky investments. Eur. Rev. Agric. Econ. 7, 147-175. https://doi.org/10.1093/erae/7.2.147

BMEL, 2015. EU-Agrarpolitik - FAQ zur Agrarreform und der nationalen Umsetzung [WWW Document]. URL http://www.bmel.de/DE/Landwirtschaft/Agrarpolitik/_Texte/GAPFAQs.html;jsessionid=0D73EAAFA1620445FB82F36E765C5694.2_cid296\#doc4121 226bodyText8 (accessed 5.29.15).

CAPRI, 2017. Common Agricultural Policy Regionalized Impact (CAPRI) Modelling System. http://www.capri-model.org/dokuwiki/doku.php?id=start (accessed 1.25.17).

Cetinkaya, E., Thiele, A., 2014. Real Options: A Survey. Lehigh University.

Consigli, G., Dempster, M. a. H., 1998. Dynamic stochastic programmingfor asset-liability management. Ann. Oper. Res. 81, 131-162. https://doi.org/10.1023/A:1018992620909

Cox, J.C., Ross, S.A., Rubinstein, M., 1979. Option pricing: A simplified approach. J. Financ. Econ. 7, 229-263. https://doi.org/10.1016/0304-405X(79)90015-1

de Oliveira, D.L., Brandao, L.E., Igrejas, R., Gomes, L.L., 2014. Switching outputs in a bioenergy cogeneration project: A real options approach. Renew. Sustain. Energy Rev. 36, 74-82. https://doi.org/10.1016/j.rser.2014.04.023

Dempster, M. a. H., 2006. Sequential Importance Sampling Algorithms for Dynamic Stochastic Programming. J. Math. Sci. 133, 1422-1444. https://doi.org/10.1007/s10958-006-00581

Dempster, M. a. H., Thompson, R.T., 1999. EVPI-based importance sampling solution proceduresfor multistage stochastic linear programmeson parallel MIMD architectures. Ann. Oper. Res. 90, 161-184. https://doi.org/10.1023/A:1018956530304

Di Corato, L., Gazheli, A., Lagerkvist, C.-J., 2013. Investing in energy forestry under uncertainty. For. Policy Econ. 34, 56-64. https://doi.org/10.1016/j.forpol.2013.06.001

Di Falco, S., Perrings, C., 2003. Crop Genetic Diversity, Productivity and Stability of Agroecosystems. A Theoretical and Empirical Investigation. Scott. J. Polit. Econ. 50, 207-216. https://doi.org/10.1111/1467-9485.5002006

Dixit, A.K., Pindyck, R.S., 1994. Investment Under Uncertainty. Princeton University Press.

Djanibekov, U., Villamor, G.B., 2017. Market-based instruments for risk-averse farmers: rubber agroforest conservation in Jambi Province, Indonesia. Environ. Dev. Econ. 22, 133-155. https://doi.org/10.1017/S1355770X16000310 
Douglas-Smith, D., Iwanaga, T., Croke, B.F.W., Jakeman, A.J., 2020. Certain trends in uncertainty and sensitivity analysis: an overview of software tools and techniques. Environ. Model. Softw. 124, 104588. https://doi.org/10.1016/j.envsoft.2019.104588

Dupačová, J., Consigli, G., Wallace, S.W., 2000. Scenarios for Multistage Stochastic Programs. Ann. Oper. Res. 100, 25-53. https://doi.org/10.1023/A:1019206915174

EC, 2019. The post-2020 Common Agricultural Policy: environmental benefits and simplification.

Escudero, L.F., Araceli Garín, M., Merino, M., Pérez, G., 2012. An algorithmic framework for solving large-scale multistage stochastic mixed 0-1 problems with nonsymmetric scenario trees. Comput. Oper. Res. 39, 1133-1144. https://doi.org/10.1016/j.cor.2011.06.021

Faasch, R.J., Patenaude, G., 2012. The economics of short rotation coppice in Germany. Biomass Bioenergy 45, 27-40. https://doi.org/10.1016/j.biombioe.2012.04.012

Feng, Y., Ryan, S.M., 2013. Scenario construction and reduction applied to stochastic power generation expansion planning. Comput. Oper. Res. 40, 9-23. https://doi.org/10.1016/j.cor.2012.05.005

Fildes, R., Nikolopoulos, K., Crone, S.F., Syntetos, A.A., 2017. Forecasting and operational research: a review. J. Oper. Res. Soc., 59:9, 1150-1172. https://doi.org/10.1057/palgrave.jors.2602597

Finger, R., 2016. Assessment of uncertain returns from investment in short rotation coppice using risk adjusted discount rates. Biomass Bioenergy 85, 320-326. https://doi.org/10.1016/j.biombioe.2015.12.028

Finger, R., Dalhaus, T., Allendorf, J., Hirsch, S., 2018. Determinants of downside risk exposure of dairy farms. Eur. Rev. Agric. Econ. 45, 641-674. https://doi.org/10.1093/erae/jby012

Flaten, O., Lien, G., 2007. Stochastic utility-efficient programming of organic dairy farms. Eur. J. Oper. Res. 181, 1574-1583. https://doi.org/10.1016/j.ejor.2005.11.053

Flisberg, P., Frisk, M., Rönnqvist, M., 2014. Integrated harvest and logistic planning including road upgrading. Scand. J. For. Res. 29, 195-209. https://doi.org/10.1080/02827581.2014.929733

Frauendorfer, K., Marohn, C., 1998. Refinement Issues in Stochastic Multistage Linear Programming, in: Marti, P.D.K., Kall, P.D.P. (Eds.), Stochastic Programming Methods and Technical Applications, Lecture Notes in Economics and Mathematical Systems. Springer Berlin Heidelberg, pp. 305-328. https://doi.org/10.1007/978-3-642-45767$8 \_19$ 
Frey, G.E., Mercer, D.E., Cubbage, F.W., Abt, R.C., 2013. A real options model to assess the role of flexibility in forestry and agroforestry adoption and disadoption in the Lower Mississippi Alluvial Valley. Agric. Econ. 44, 73-91. https://doi.org/10.1111/j.15740862.2012.00633.X

GAMS, 2015. GAMS Documentation 24.6; Tools; Data Transformation; SCENRED2. http://www.gams.com/latest/docs/tools/scenred2/index.html (accessed 1.25.16).

Gandorfer, M., Eckstein, K., Hoffmann, H., 2011. Modeling Economic Performance of an Agroforestry System under Yield and Price Risk. Presented at the Paper prepared for presentation at the 15th International Consortium on Applied Bioeconomy Research (ICABR) Annual Conference.

Geske, R., Johnson, H.E., 1984. The American Put Option Valued Analytically. J. Finance 39, 1511-1524. https://doi.org/10.1111/j.1540-6261.1984.tb04921.x

Guthrie, G., 2009. Real Options in Theory and Practice. Oxford University Press.

Haigh, M.S., Holt, M.T., 2002. Combining time-varying and dynamic multi-period optimal hedging models. Eur. Rev. Agric. Econ. 29, 471-500. https://doi.org/10.1093/eurrag/29.4.471

Haugh, M.B., Kogan, L., 2004. Pricing American Options: A Duality Approach. Oper. Res. 52, 258-270. https://doi.org/10.1287/opre.1030.0070

Heitsch, H., Römisch, W., 2008. Scenario tree reduction for multistage stochastic programs. Comput. Manag. Sci. 6, 117-133. https://doi.org/10.1007/s10287-008-0087-y

IBM, 2016. IBM CPLEX Optimizer: software's background and support. http://www01.ibm.com/software/commerce/optimization/cplex-optimizer/ (accessed 2.16.16).

Kallio, M., Kuula, M., Oinonen, S., 2012. Real options valuation of forest plantation investments in Brazil. Eur. J. Oper. Res. 217, 428-438. https://doi.org/10.1016/j.ejor.2011.09.040

Klaassen, P., 1998. Financial Asset-Pricing Theory and Stochastic Programming Models for Asset/Liability Management: A Synthesis. Manag. Sci. 44, 31-48. https://doi.org/10.1287/mnsc.44.1.31

KTBL, 2016. Kuratorium für Technik und Bauwesen in der Landwirtschaft e.V. "LeistungsKostenrechnung Pflanzenbau" [WWW Document]. URL http://daten.ktbl.de/dslkrpflanze/postHv.html\#Ergebnis (accessed 8.3.16).

Lander, D.M., Pinches, G.E., 1998. Challenges to the practical implementation of modeling and valuing real options. Q. Rev. Econ. Finance 38, 537-567. https://doi.org/10.1016/S1062-9769(99)80089-1 
Létourneau, P., Stentoft, L., 2014. Refining the least squares Monte Carlo method by imposing structure. Quant. Finance 14, 495-507. https://doi.org/10.1080/14697688.2013.787543

Lewandowski, I., 2015. Securing a sustainable biomass supply in a growing bioeconomy. Glob. Food Secur. 6, 34-42. https://doi.org/10.1016/j.gfs.2015.10.001

Longstaff, F.A., Schwartz, E.S., 2001. Valuing American Options by Simulation: A Simple Least-Squares Approach. Rev. Financ. Stud. 14, 113-147. https://doi.org/10.1093/rfs/14.1.113

Lothner, D.C., Hoganson, H.M., Rubin, P.A., 1986. Examining short-rotation hybrid poplar investments by using stochastic simulation. Can. J. For. Res. 16, 1207-1213. https://doi.org/10.1139/x86-215

Marinoni, O., Higgins, A., Hajkowicz, S., Collins, K., 2009. The multiple criteria analysis tool (MCAT): A new software tool to support environmental investment decision making. Environ. Model. Softw. 24, 153-164. https://doi.org/10.1016/j.envsoft.2008.06.015

Merton, R.C., 1973. Theory of Rational Option Pricing. Bell J. Econ. Manag. Sci. 4, 141-183. https://doi.org/10.2307/3003143

Metcalf, G.E., Hassett, K.A., 1995. Investment under alternative return assumptions Comparing random walks and mean reversion. J. Econ. Dyn. Control 19, 1471-1488. https://doi.org/10.1016/0165-1889(94)00838-9

Musshoff, O., 2012. Growing short rotation coppice on agricultural land in Germany: A Real Options Approach. Biomass Bioenergy 41, 73-85. https://doi.org/10.1016/j.biombioe.2012.02.001

O’Regan, B., Moles, R., 2001. An insight into the system dynamics method: a case study in the dynamics of international minerals investment. Environ. Model. Softw. 16, 339-350. https://doi.org/10.1016/S1364-8152(00)00087-6

Parra-López, C., Holley, M., Lindegaard, K., Sayadi, S., Esteban-López, G., Durán-Zuazo, V.H., Knauer, C., Engelbrechten, H.-G. von, Winterber, R., Henriksson, A., Lamley, A., Nylander, A., Paulrud, S., Leonard, P., Daly, P., Drzewaszewski, L., Rzewuski, W., 2017. Strengthening the development of the short-rotation plantations bioenergy sector: Policy insights from six European countries. Renew. Energy 114, 781-793. https://doi.org/10.1016/j.renene.2017.07.098

Pecenka, R., Hoffmann, T., 2012. Harvest Technology for short rotation coppices and costs of harvest, transport and storage. Agron. Res. 13, 361-371.

Regan, C.M., Bryan, B.A., Connor, J.D., Meyer, W.S., Ostendorf, B., Zhu, Z., Bao, C., 2015. Real options analysis for land use management: Methods, application, and implications 
for policy. J. Environ. Manage. 161, 144-152. https://doi.org/10.1016/j.jenvman.2015.07.004

Rogers, L.C.G., 2002. Monte Carlo valuation of American options. Math. Finance 12, 271-286. https://doi.org/10.1111/1467-9965.02010

Rokwood, 2014. Findings of the SWOT analysis. Centre for Sustainable Energy.

Sabour, S.A.A., Poulin, R., 2006. Valuing Real Capital Investments Using The Least-Squares Monte Carlo Method. Eng. Econ. 51, 141-160. https://doi.org/10.1080/00137910600705210

Sagastizábal, C., 2012. Divide to conquer: decomposition methods for energy optimization. Math. Program. 134, 187-222. https://doi.org/10.1007/s10107-012-0570-7

Schuler, J., Bues, A., Henseler, M., Krämer, C., Krampe, L., Kreins, P., Liebersbach, H., Osterburg, B., Röder, N., Uckert, G., 2014. Instrumente zur Stärkung von Synergien zwischen Natur- und Klimaschutz im Bereich Landbewirtschaftung. BfN-Skripten.

Schweier, J., Becker, G., 2013. Economics of poplar short rotation coppice plantations on marginal land in Germany. Biomass Bioenergy 59, 494-502. https://doi.org/10.1016/j.biombioe.2013.10.020

Schweier, J., Becker, G., 2012. New Holland Forage Harvester's Productivity in Short Rotation Coppice: Evaluation of Field Studies from a German Perspective. Int. J. For. Eng. 23, 82-88. https://doi.org/10.1080/14942119.2012.10739964

Simoglou, C.K., Kardakos, E.G., Bakirtzis, E.A., Chatzigiannis, D.I., Vagropoulos, S.I., Ntomaris, A.V., Biskas, P.N., Gigantidou, A., Thalassinakis, E.J., Bakirtzis, A.G., Catalão, J.P.S., 2014. An advanced model for the efficient and reliable short-term operation of insular electricity networks with high renewable energy sources penetration. Renew. Sustain. Energy Rev. 38, 415-427. https://doi.org/10.1016/j.rser.2014.06.015

Smith, J.E., 2005. Alternative Approaches for Solving Real-Options Problems. Decis. Anal. 2, 89-102. https://doi.org/10.1287/deca.1050.0041

Song, F., Zhao, J., Swinton, S.M., 2011. Switching to Perennial Energy Crops Under Uncertainty and Costly Reversibility. Am. J. Agric. Econ. 93, 768-783. https://doi.org/10.1093/ajae/aar018

Spiegel, A., Britz, W., Djanibekov, U., Finger, R., 2018. Policy analysis of perennial energy crop cultivation at the farm level: Short rotation coppice (SRC) in Germany. Biomass Bioenergy 110, 41-56. https://doi.org/10.1016/j.biombioe.2018.01.003 
Spiegel, A., Britz, W., Finger, R., 2017. A real-option farm-level model on investment in perennial energy crops under risk considerations. https://doi.org/10.3929/ethz-b000219189

StAmtMV, 2016.

http://www.statistik-

mv.de/cms2/STAM_prod/STAM/de/ep/Regionaldaten\%2c_Datenbanken/index.jsp (accessed 8.2.16).

Stentoft, L., 2004. Assessing the Least Squares Monte-Carlo Approach to American Option Valuation. Rev. Reriv. Res. 1, 129-168. https://doi.org/10.1023/B:REDR.0000031176.24759.e6

Strauss, C.H., Grado, S.C., Blankenhorn, P.R., Bowersox, T.W., 1988. Economic evaluations of multiple rotation sric biomass plantations. Sol. Energy 41, 207-214. https://doi.org/10.1016/0038-092X(88)90138-7

Tee, J., Scarpa, R., Marsh, D., Guthrie, G., 2014. Forest Valuation under the New Zealand Emissions Trading Scheme: A Real Options Binomial Tree with Stochastic Carbon and Timber Prices. Land Econ. 90, 44-60. https://doi.org/10.3368/le.90.1.44

Tolbert, V.R., Todd, D.E., Mann, L.K., Jawdy, C.M., Mays, D.A., Malik, R., Bandaranayake, W., Houston, A., Tyler, D., Pettry, D.E., 2002. Changes in soil quality and belowground carbon storage with conversion of traditional agricultural crop lands to bioenergy crop production. Environ. Pollut. 116, S97-S106. https://doi.org/10.1016/S0269-7491(01)00262-7

Trigeorgis, L., 1991. A Log-Transformed Binomial Numerical Analysis Method for Valuing Complex Multi-Option Investments. J. Financ. Quant. Anal. 26, 309-326. https://doi.org/10.2307/2331209

Trigeorgis, L., 1996. Real Options: Managerial Flexibility and Strategy in Resource Allocation. MIT Press.

Trigeorgis, L., Reuer, J.J., 2017. Real options theory in strategic management. Strat. Mgmt. J. $38,42-63$.

Trigeorgis, L., Tsekrekos, A.E., 2018. Real options in operations research: a review. Eur. J. Oper. Res. 270(1), 1-24. https://doi.org/10.1016/j.ejor.2017.11.055

Uusitalo, L., Lehikoinen, A., Helle, I., Myrberg, K., 2015. An overview of methods to evaluate uncertainty of deterministic models in decision support. Environ. Model. Softw. 63, 2431. https://doi.org/10.1016/j.envsoft.2014.09.017 
van Ackooij, W., Sagastizábal, C., 2014. Constrained Bundle Methods for Upper Inexact Oracles with Application to Joint Chance Constrained Energy Problems. SIAM J. Optim. 24, 733-765. https://doi.org/10.1137/120903099

Venter, P. van Z., Terblanche, S.E., van Eldik, M., 2018. Turbine investment optimisation for energy recovery plants by utilising historic steam flow profiles. Energy 155, 668-677. https://doi.org/10.1016/j.energy.2018.04.186

Viaggi, D., Raggi, M., Gomez y Paloma, S., 2013. Modelling and interpreting the impact of policy and price scenarios on farm-household sustainability: Farming systems vs. resultdriven clustering. Environ. Model. Softw. 43, 96-108. https://doi.org/10.1016/j.envsoft.2013.01.014

WetterOnline, http://www.wetteronline.de (accessed 12.9.15).

Wolbert-Haverkamp, M., Musshoff, O., 2014. Are short rotation coppices an economically interesting form of land use? A real options analysis. Land Use Policy 38, 163-174. https://doi.org/10.1016/j.landusepol.2013.10.006

Wühlisch, G. von, 2016. Pappeln und Weiden in Deutschland: Bericht der Nationalen Pappelkommission 2012-2015. Johann Heinrich von Thünen-Institut, Germany.

Yan, S., Ji, X., 2017. Portfolio selection model of oil projects under uncertain environment. Soft Comput. https://doi.org/10.1007/s00500-017-2619-2

Zhu, L., Fan, Y., 2011. A real options-based CCS investment evaluation model: Case study of China's power generation sector. Appl. Energy 88, 4320-4333. https://doi.org/10.1016/j.apenergy.2011.04.005 